\title{
Fire performance of innovative steel-concrete composite columns using
}

\section{high strength steels}

\author{
Ana Espinos ${ }^{a, *}$, Manuel L. Romero ${ }^{a}$, Dennis Lam ${ }^{b}$ \\ ${ }^{a}$ Instituto de Ciencia y Tecnología del Hormigón (ICITECH), \\ Universitat Politècnica de València, Valencia, Spain \\ ${ }^{b}$ School of Engineering, Faculty of Engineering \& Informatics, \\ University of Bradford, Bradford, United Kingdom \\ *Corresponding author.e-mail address: aespinos@mes.upv.es
}

\begin{abstract}
This paper presents the results of a numerical investigation on strategies for enhancing the fire behaviour of concrete-filled steel tubular (CFST) columns by using inner steel profiles such as circular hollow sections (CHS), HEB profiles or embedded steel core profiles. A threedimensional finite element model is developed for that purpose, which is capable for representing the various types of sections studied and the nonlinear behaviour of the materials at elevated temperatures. High strength steel is considered in the numerical model, as a possible way to lengthen the fire endurance. The numerical model is validated against experimental results available in the literature for various types of steel-concrete composite sections using inner steel profiles, obtaining satisfactory results. Based on the developed numerical model, parametric studies are conducted for investigating the influence of the cross-sectional geometry and the steel grade of the inner profiles on the fire performance of these composite columns, for eventually providing some practical recommendations.
\end{abstract}

Keywords: Fire resistance; Steel-concrete composite sections; Concrete-filled steel tubular columns; Concrete-filled double steel columns; Embedded steel profiles; High strength steel 


\section{NOTATION}
$A_{c} \quad$ Area of concrete
$A_{s}$
Area of steel
B.C. Boundary conditions
CFDST Concrete-filled double steel tube
CFST Concrete-filled steel tube
CFST-HEB Concrete-filled steel tube with inner HEB profile
CFSTES Concrete-filled steel tube with embedded steel core
CHS Circular hollow section
$D_{\text {core }} \quad$ Diameter of the inner steel core
$D_{i} \quad$ Diameter of the inner steel tube (CFDST)
Do $\quad$ Diameter of the outer steel tube (CFDST)
$e \quad$ Load eccentricity
$f_{c} \quad$ Compressive cylinder strength of concrete
$f_{c i} \quad$ Compressive cylinder strength of the inner concrete core
$f_{c o} \quad$ Compressive cylinder strength of the outer concrete ring
$f_{s} \quad$ Yield strength of reinforcing steel
$f_{y} \quad$ Yield strength of structural steel
$f_{y, \text { core }} \quad$ Yield strength of the inner steel core
$f_{y i} \quad$ Yield strength of the inner steel profile
$f_{y o} \quad$ Yield strength of the outer steel tube
HSS High strength steel
$L \quad$ Length of the column
$N_{\text {applied }} \quad$ Applied axial load
$N_{b, R d} \quad$ Design axial buckling load of the column at room temperature
$t_{i} \quad$ Wall thickness of the inner steel tube (CFDST)
$t_{o} \quad$ Wall thickness of the outer steel tube (CFDST)
$\bar{\lambda} \quad$ Relative slenderness of the column at room temperature 


\section{INTRODUCTION}

Concrete-filled steel tubular (CFST) columns offer high load-bearing capacity with reduced sectional dimensions and therefore they are increasingly being used in the construction of high-rise buildings. However, there are some concerns on the fire performance of slender columns that failed prematurely [1]-[4]. Innovative solutions are therefore sought to help to improve the performance of this type of composite columns in the fire situation.

Recently, innovative steel-concrete composite solutions have been developed, which can solve the current limitations of slender CFST members when exposed to fire. One of this solutions are the so-called concrete-filled double-skin tubes, which have the potential to be used as columns in high-rise buildings, bridge piers or transmission towers [5][6]. In this tube-intube configuration, the inner steel tube is thermally protected by the outer concrete ring and therefore its degradation is delayed, which may help resisting the applied load for a longer period of time, solving the aforementioned problems of slender CFST columns in the fire situation.

Extensive research has been conducted on CFDST members at ambient temperature [7][13], although there is very limited knowledge about the fire performance of such columns.

Lu et al. [14]-[16] performed a series of fire tests on concrete-filled double-skin tubes (CFDST) on a collaborative project between Monash University and Tsinghua University, studying both stub and slender columns. The critical or limiting temperature for double-skin sections was found to be higher than for CFST sections, due to the thermal protection of the inner steel tube offered by the concrete ring. Six full size double-skin columns were tested, four of them unprotected and another two protected by spray fire resistant coating. 16 stub columns filled with self-compacting concrete (some of them fibre reinforced) were also tested. It was found that the added fibre did not affect the temperature distribution, whereas the increased 
concrete thickness and outer tube perimeter reduced the temperature of the section. The added steel fibre was also found to increase the fire resistance of stub columns at reduced load levels.

The fire performance of these columns can be enhanced even more by adding concrete inside the inner tube, constituting the so-called double-tube columns (Fig. 1a), where both the inner and outer tube are filled with concrete. Filling the inner steel tube with concrete contributes to increase the load-bearing capacity of the column, while it delays the temperature rise within the column cross-section and therefore lengthens its fire resistance. Romero et al. [17] recently carried out an extensive experimental campaign where both double-skin and double-tube slender concrete-filled tubular columns were tested, reporting a series of six tests at room temperature and other six tests at elevated temperature. Normal (C30) and ultra-high strength $(\mathrm{C} 150)$ concrete were used for filling the columns. The influence of filling the inner tube with concrete was studied, as well as the variation of thicknesses of the outer and inner steel tubes. It was found that a good design strategy for CFST columns is to split the outer tube into two different steel tubes with the same total steel area (and thus same steel usage), placing the thinner tube in the outer part of the section and the thicker tube in the inner part for thermal protection. Both rings should be filled up with concrete for an enhanced fire performance. These conclusions have been recently confirmed by the authors [18].

Other innovative solutions, such as embedding HEB profiles or massive steel cores inside a traditional CFST column (Fig. 1b, c) can be found in the literature, although these solutions have not been intensively studied. These solutions may offer important advantages in terms of structural performance, economy and architectural interest. Their high load-bearing capacity at relatively high slenderness ratios makes them architecturally appealing, while their fire performance is exceptional, as the temperature rise within the steel profile or steel core and therefore their loss of strength and stiffness are delayed by the protection of the concrete infill. 
Amongst the scarce investigations that can be found on CFST columns with embedded HEB profiles, the work from Chu et al. [19]-[22] can be cited. In this research, ten columns filled with self-compacting concrete embedding another steel profile were tested at elevated temperature in the Fire Engineering Laboratory of the University of Liege (Belgium). This work not only contained CFST columns with embedded HEB profile, but also double-tube columns. Out of the ten columns being tested, two of them were protected by intumescent coating. Five different cross-sections were used, and two tests were performed for each section: CHS inside CHS (with two different dimensions), SHS inside CHS, HEB profile inside CHS and HEB profile inside SHS. Only four of the columns used an embedded HEB profile, therefore further research is needed.

In turn, CFST columns with massive embedded steel core (Fig. 1c) have been studied by Neuenschwander et al. [23][24]. A fire testing program of four concrete filled circular hollow section columns with solid steel core was presented. The tests were carried out at the laboratories of the Technical University of Brunswick (Germany). Also Schaumann and Kleiboemer [25][26] have recently carried out investigations on the fire behaviour of such columns. One large scale fire test was carried out at the laboratories of BAM Berlin (Germany) and a series of stub columns push-out tests were also performed at the Leibniz University Hannover (Germany) to investigate the composite action between the steel core and the surrounding concrete at both room and elevated temperature, a necessary basis for the subsequent development of numerical models. However, further experimental testing on this type of innovative composite sections is needed, in order to establish accurately their fire performance and determine the evolution of shear stresses [27] at the steel-concrete interface.

This paper aims at developing a design strategy for maximizing the fire resistance of CFST columns by using innovative solutions such as double-tube sections, embedded HEB 
profiles or embedded steel cores. Also, the fire performance of such columns may be enhanced by using high strength steels (HSS).

In Europe, structural steel is classified as HSS if its yield strength exceeds $460 \mathrm{MPa}$. These steels are acquiring an increasing popularity in the construction industry, owing to their excellent mechanical properties. Buildings of recent construction have used HSS, such as the "Freedom Tower" in New York (USA), the Olympic Stadium "Bird's Nest" in Beijing (China) or the Millau viaduct (France) [28]. In Japan, a new building in Kiyose City uses CFST columns combining $700 \mathrm{MPa}$ HSS with ultra-high strength concrete [29].

In structural steelwork design, high strength steel allows the usage of less material, which reduces the costs associated to construction, transport and assembly. However, regarding their behaviour at elevated temperature, little information exists in the literature and the building codes do not include design recommendations for this type of steels in the fire condition. EN1993-1-12 [30], related to HSS up to S700 grade does not provide any additional information on the fire design of such steel grades, and practitioners are referred to EN1993-1-2 [31], valid up to S460 grade. Very limited research has been carried out to date on the fire behaviour of HSS. Amongst the existing work, results from Lange and Wohlfeil [32], Schneider and Lange [33] and Outinen [34] on HSS S460, or Chen and Young [35][36] and Chiew et al. [37] for HSS S690 can be found. Qiang et al. [28][38]-[42], investigated the mechanical properties of HSS S460, S690 and S960 at elevated temperatures, proposing reduction coefficients for these steels based on experimental results. Recent work from Choi et al. [43] and Zhao et al. [44] can also be found in the literature.

The presented advantages of high strength steel open a new range of possibilities regarding its application in CFST columns, where it can result of great utility to solve the problem of the limited fire resistance of slender members. In fact, Tondini et al. [29] presented 
recently the results of a fire test on a CFST column using HSS, where the superior performance of composite columns made of HSS was proved.

Taking advantage of the improved properties of HSS and using the appropriate steel share between the outer tubes and inner profiles with the innovative sections proposed in this paper, it could be possible to obtain an elevated fire resistance without the need of external protection, saving the subsequent cost and time.

In this paper, three different types of innovative steel-concrete composite columns will be numerically studied, see Fig. 1: double-tube columns (CFDST, type I), CFST columns with embedded HEB profiles (CFST-HEB, type II) and CFST columns with embedded steel core (CFSTES, type III). The fire performance of such sections will be compared and, through the results of a parametric study, strategies will be designed for enhancing the fire resistance of CFST columns by using inner profiles made of HSS.

\section{FINITE ELEMENT MODELLING}

A three-dimensional numerical model was developed by Espinos et al. [45] using the general purpose nonlinear finite element analysis package ABAQUS [46]. This numerical model had been previously used by the authors with satisfactory results for simulating the fire behaviour of CFST columns, having been validated against an extensive series of experimental results. The numerical model is now adapted for CFST columns with inner steel profiles, as described in the following subsections.

\subsection{Geometry and finite element mesh}

Different parts are assembled to compose the geometries to be studied in this paper: outer steel tube, concrete encasement, inner profiles - steel tube, HEB profile or steel core - and steel end plates. 
The steel end plates are modelled as discrete rigid parts with all nodes coupled to a reference point located at the column axis. The axial load is applied to the upper rigid plate through its reference node.

The outer steel tube, concrete encasement and inner profiles are meshed using threedimensional eight-noded solid elements with reduced integration (C3D8R). In turn, the steel end plates are meshed using four-noded three-dimensional bilinear rigid quadrilateral elements (R3D4). Based on the results of a mesh sensitivity study, a maximum finite element size of 20 $\mathrm{mm}$ is used. Fig. 2 shows the finite element mesh of the different type of columns analysed.

\subsection{Boundary conditions}

Depending on the test specimen being compared, the specific boundary conditions given in the literature are used. For the parametric studies that are presented later, pinned-pinned end conditions are considered in all the numerical simulations. These symmetric boundary conditions, as well as the sectional symmetry and uniform fire exposure, allow only one-quarter of the column specimens to be modelled, thus saving a considerable amount of computational time. Following these boundary conditions, the mid-section of the column is restricted in all the directions except for the lateral displacement, while the upper rigid plate is allowed to move along the column axis and rotate in the perpendicular axis, and it is fixed against the other four degrees of freedom.

\subsection{Initial imperfection}

The numerical model takes into account the initial geometric imperfection of the columns, which is obtained from an eigenvalue analysis as the first buckling mode shape of a hinged column. Once the initial deformed shape of the column is obtained, it is imported to the mechanical model as the starting geometry, multiplied by an amplification factor corresponding 
to the maximum imperfection of the column. A value of $L / 1000$ is used in all the simulations, as this value proved to give accurate results in the previous works from the authors [45].

\subsection{Analysis procedure}

A sequentially coupled thermal-stress analysis is used in the simulations. This approach consists of first conducting a pure heat transfer analysis by computing the temperature field following by a stress/deformation analysis for calculating the structural response. In the initial thermal analysis, the columns are uniformly exposed to the standard ISO-834 fire curve along their length. In the mechanical analysis, the columns are first loaded and the constant applied load is maintained, while the output from the thermal analysis (nodal temperature-time curves) is imported into the mechanical model as a predefined field, representing the temperature evolution inside the column during the fire exposure. It should be pointed out that this analysis procedure is only valid for those columns that follow a standard fire test procedure. If a different thermal or mechanical loading sequence was followed in any of the tests used for validation, the authors have tried to replicate it in the model.

\subsection{Steel-concrete composite behaviour}

The mechanical interaction between the contacting surfaces of the different steel profiles (outer tube or inner profiles) and the concrete encasement is modelled as follows. In the normal direction, a "hard point" contact formulation is used, which allows any pressure value when the surfaces are in contact and transmits no pressure when the surfaces do not contact. For the tangent interaction, the Coulomb friction model is employed, with a value of 0.3 for the friction coefficient.

The same steel-concrete mechanical interaction is used to take into account the contact between the ends of the concrete core and inner profiles and the rigid plates. Relative 
displacement between the outer steel tube and the rigid end plates is prevented by means of a "tie" constraint.

The thermal resistance at the boundary between the outer steel tube and the concrete encasement is taken into account in the numerical model. Based on the results of previous investigations [45], a constant gap conductance value of $200 \mathrm{~W} / \mathrm{m}^{2} \mathrm{~K}$ is used for modelling the thermal resistance at this interface. However, for modelling the contact between the concrete infill and the inner profiles, a "perfect thermal contact" is considered, i. e. all the heat is transferred from the concrete to the inner profile without delay, as the concrete encasement prevents the transversal separation and therefore these surfaces remain in contact during all the fire exposure.

The current version of EN 1994-1-2 [47] does not provide any recommendations for values of shear stresses that can be transferred between inner steel profiles and concrete in composite columns at elevated temperatures. In turn, EN 1994-1-1 [48] only contains values for few cross-sections and does not provide values for CFST-HEB or CFSTES columns. A series of experimental tests carried out by Schaumann and Kleiboemer [25] in the framework of the former RFCS European project FRISCC revealed that the capable shear stresses of CFSTES are much higher at room temperature than any value provided in EN 1994-1-1 [48]. In contrast, the tests showed a significant reduction of shear stresses at higher temperatures, however it was only verified for CFSTES columns. It is to be expected that the type of inner steel profile has a major influence on the maximum shear stresses, as well as the friction coefficient after exceeding the maximum load, therefore further experimental investigations are needed for characterizing this composite behaviour for the different types of innovative sections.

\subsection{Material modelling at elevated temperatures}


The temperature dependent thermal and mechanical properties of the materials are accounted for in the numerical model.

To represent the mechanical behaviour of steel, an isotropic elastic-plastic model with the von Mises yield criterion is used. The constitutive model selected to characterise the uniaxial behaviour of normal strength steel at elevated temperatures is taken from EN 1993-1-2 [31].

The Poisson's ratio of steel is assumed to be independent of the temperature, being equal to 0.3. Moreover, the temperature dependent thermal properties given in EN 1993-1-2 [31] are adopted - specific heat, thermal conductivity and thermal elongation -.

For the modelling of the behaviour of high strength steel (HSS) at elevated temperatures, the shape of the constitutive laws given in EN1993-1-2 [31] is used, together with the reduction factors proposed by Qiang et al. [28][38]-[42] for HSS, as the model in EN1993-1-2 applies only to steel grades up to S460. The yield strength reduction factors proposed by Qiang for the different steel grades (S460, S690 and S960) at elevated temperatures are given in Fig. 3, where they are compared with the reduction factors for the normal strength steel from EN1993-1-2 [31].

For characterizing the mechanical behaviour of concrete at elevated temperatures, a Drucker Prager model is used. The stress-strain relations for concrete under compression given in EN 1992-1-2 [49] are employed. The initial elastic behaviour at each temperature is defined by means of the elastic modulus and Poisson's ratio. The Poisson's ratio of concrete is assumed to be independent of the temperature, being equal to 0.2 .

The thermal properties for concrete at elevated temperatures are obtained from EN 19921-2 [49]. For the thermal conductivity, the upper limit is used, as recommended in Note 2, Clause 3.3.2(9) of EN 1992-1-2 for steel-concrete composite structural elements. A $4 \%$ moisture content is assumed in the simulations, as given in Clause 3.3.2(7). The latent heat of 
water vaporisation is taken into account through a peak value in the specific heat formulation between 100 and $200^{\circ} \mathrm{C}$, as per the Clause 3.3.2(8).

\subsection{Residual stresses}

In previous investigations, Hamme and Schaumann [27] proved that massive steel profiles present residual stresses of significant magnitude, which cannot be neglected. Therefore, structural imperfections are considered for the steel core in the numerical simulations of CFSTES columns. This is done by performing a previous simulation of the cooling process of the steel core, where it is allowed to freely cool down from an initial temperature of $1200{ }^{\circ} \mathrm{C}$ to ambient temperature. Once the steel core is cold, the resulting residual stress distribution obtained from this preliminary model is transferred to the main model.

\section{VALIDATION OF THE NUMERICAL MODEL}

In this section, the described numerical model is validated by comparing the results with experimental tests on the three types of sections studied: concrete-filled double steel tube (CFDST) columns (type I), CFST columns with embedded HEB profiles (type II) and CFST columns with embedded steel core (type III).

\subsection{Validation of type I sections (CFDST)}

The numerical model is validated for concrete-filled double steel tube (CFDST) columns in the first instance - double-skin and double-tube -. Experimental results are available from previous investigations by the authors [17], as well as from a previous research from Lu et al. [14]-[16]. The columns used for the comparison are summarized in Table 1a.

On the first stage, the numerical model is validated against four of the tests performed by Romero et al. [17]. From the reported research, four out of six columns are used, those filled 
with C30 grade concrete, as this investigation is limited to normal strength concrete. Two of the columns presented a double-skin configuration (C200-3-30_C114-8-00, C200-6-30_C1143-00) - i.e. without concrete inside the inner tube -, while the other two were also filled with concrete inside the inner tube, therefore resulting in the so-called double-tube configuration (C200-3-30_C114-8-30, C200-6-30_C114-3-30). All of the columns were tested under concentric load and hinged at both ends. Fig. 4 shows a comparison in terms of axial displacement measured at the top end of the column for two specimens from Romero et al. [17].

On the second stage, the model is validated by comparison with the fire tests on doubleskin columns reported by Lu et al. [14], see Table 1a. Six full size column specimens are available for comparison, from where specimens CC2 and CC3 are selected, being the only ones with the geometry of interest in this study (CHS used for the outer and inner tube) and without fire protection, as it is out of the scope of this paper. One of the columns was eccentrically loaded (CC2), while column CC3 was tested under concentric load. The results of the numerical simulations compared with the experimental axial displacement curves for these two tests are given in Fig. 5.

It can be seen in both Fig. 4 and Fig. 5 that there is a good agreement between the numerical and experimental results, for both the own tests and those from $\mathrm{Lu}$ et al, except for a slight deviation over the measured axial displacement observed in the numerical simulation of specimen CC3 (Fig. 5b). The prediction of the failure time was accurate in all cases, therefore, the model is considered reliable for representing the fire behaviour of concrete-filled doubleskin and double-tube columns.

\subsection{Validation of type II sections (CFST-HEB)}

For the case of type II sections, CFST columns with embedded HEB profile, the experimental results from Dotreppe et al. [19] [20] are used for validation, see Table 1b. From the reported tests, specimens $3 \mathrm{~A}$ and $4 \mathrm{~A}$ are used, the former consisting of a circular hollow 
steel tube of $219.1 \times 5 \mathrm{~mm}$ with an embedded HEB 120 profile and the latter being a square hollow steel tube of $200 \times 5 \mathrm{~mm}$ with the same embedded profile. Tests $3 \mathrm{~B}$ and $4 \mathrm{~B}$ are not included in this comparison, as these columns were protected with intumescent paint. A small eccentricity of $10 \mathrm{~mm}$ was applied to the column ends in order to induce the buckling of the column.

In the numerical simulations, the inner HEB profile was tied to the upper steel plate and a rotational stiffness was applied to the column end, in order to capture the experimental observations, which deviated from the nominal boundary conditions.

Fig. 6 shows the comparison between the measured and calculated axial displacement at the top end of the column for the simulated specimens from Dotreppe et al. [20]. The numerical result from these authors has been also superimposed in this figure as a reference. It can be seen that the numerical simulations are close to those from the reference model and predict well the failure time. However, the axial displacement is higher than that registered in the tests for both models, which could be due to errors in the experimental measurements.

\subsection{Validation of type III sections (CFSTES)}

The numerical model for type III sections is validated against the experimental results reported by Neuenschwander et al. [23], see Table 1c. In this research, four tests were carried out on concrete-filled CHS columns with embedded steel core. The four column specimens are used for validation. The columns were filled with C25/30 grade concrete. One of the columns was tested under pinned-pinned end conditions (SP1), while the other three were pinned-fixed. All the columns were loaded with a small eccentricity of $10 \mathrm{~mm}$ for ensuring a determined direction of buckling failure.

Following the recommendations by Neuenschwander et al. [23], the influence of eventual deviations from the nominal boundary conditions during the test were analysed and adjusted boundary conditions were developed, using axial and rotational springs in the model. A high 
rotational stiffness was introduced at the column ends, so as to reproduce the experimental observations.

A second comparison is carried out against the results of a recent fire test performed by Schaumann and Kleiboemer [25][26] at the test facilities of BAM Federal Institute for Materials Research and Testing in Berlin, in the framework of the European Project FRISCC. The test details can be seen in Table 1c. This case was a circular hollow section column of $219.1 \times 4.5$ $\mathrm{mm}$ with embedded circular steel core of $140 \mathrm{~mm}$ diameter and filled with normal strength concrete. Pinned-fixed boundary conditions were applied, with $7 \mathrm{~mm}$ eccentricity. In this fire test, the load was kept constant corresponding to a utilisation factor of 0.37 based on the resistance at room temperature. During the fire test, the column was heated according to the ISO standard fire. The column resisted the mechanical loading and temperature for about 110 minutes and was displacement-controlled compressed afterwards until failure occurred.

To reproducing this test, which did not follow the standard procedure, the simulation was divided into two stages. In the first stage, the column was subjected to the ISO standard fire during 110 minutes together with a constant load of $1800 \mathrm{kN}$. In the second stage, an increasing displacement was prescribed to the column top end while heating continued, until the final failure occurred.

Residual stresses have been considered for the embedded steel core in the numerical simulations of CFSTES columns, as described in Section 2.7.

With all these considerations, the numerical simulations of the columns with embedded steel core profiles were performed. Fig. 7a presents the comparison in terms of axial displacement measured at the top end of the column for specimen SP1 from Neuenschwander et al. [23]. In turn, Fig. 7b shows the results of the validation of the numerical model by comparison with the test specimen from Schaumann and Kleiboemer [25]. 
It can be seen that, for both case specimens compared, the failure time is well captured, although the numerical model predicts a higher axial displacement than that measured in the test in the experiments from Neuenschwander et al. [23]. This difference in axial displacement is judged reasonable, given the various uncertainties within the test data, such as the heating condition along the length of the column, the degree of axial and rotational restraint at the column ends or the deviation from the nominal value of the load eccentricity.

\subsection{Extension of the model to HSS}

After an extensive literature review on composite sections using HSS, only one fire test was found, performed by Tondini et al. [29] on a CFST column (specimen C4), where the hollow steel section was made of HSS. That test specimen is used in this research for validating the numerical model for its use with HSS. The column specimen consisted of a hollow steel tube of grade S590 filled with C30/37 concrete and using B450C type rebars. However, the measured yield strength of the steel tube was much higher than the nominal value, reaching 822 MPa yield strength. The measured properties of the materials, as well as the rest of input data, are given in Table 1d. The column was tested under pinned end conditions and, as in other tests compared, an eccentricity of $10 \mathrm{~mm}$ was given to the load at both ends in order to force the column to buckle.

For simulating this experimental test, the material behaviour of HSS at elevated temperatures was incorporated into the numerical model as described in Section 2.6 of this paper, using the constitutive equations in EN1993-1-2 [31] together with the reduction factors proposed by Qiang et al. [28][38]-[42].

Fig. 8 shows a comparison in terms of axial displacement measured at the top end of the column between the numerical simulation and the test result of the described specimen $\mathrm{C} 4$ from Tondini et al. [29]. It can be seen that the numerical model predicts well the fire behaviour of CFST columns with HSS, with a good estimation of the axial displacement along the fire 
exposure time, capturing well the elongation of the outer steel tube and its subsequent yielding and shortening due to thermal degradation.

Although given the lack of experimental results available in the literature on steelconcrete composite columns making use of HSS, only one column specimen could be compared in this section, the accuracy of using this material model for HSS has been proved and is considered acceptable at this stage, in the absence of more sources for validation. Therefore, as a preliminary model for estimating the fire performance of innovative CFST sections with inner HSS profiles, the reduction coefficients from Qiang et al. [28][38]-[42] will be used for S460, S690 and S960 steel grades in the subsequent parametric studies.

\subsection{Summary of the validation}

A summary of the validation of the numerical model is presented in Table 2 and Fig. 9, where a good agreement is observed in terms of failure time, which was especially difficult in this study given the variety of sections studied, the different experimental sources compared and the lack of more specific data on the details from the test setups. The numerical simulations are mostly conservative and close to the experimental values, therefore the numerical model is considered reliable for conducting parametric studies on innovative steel-concrete composite columns using high strength steels.

\section{PARAMETRIC STUDY}

\subsection{Description of the selected composite columns}

A parametric study was carried out in order to analyse the interest of using the innovative sections proposed in this paper for improving the fire performance of CFST columns. An initial CFST section of $273 \times 12.5 \mathrm{~mm}$ was chosen as a reference, and the amount of steel employed by that section was used to generate other three innovative sections with inner profiles (CFDST, CFST-HEB and CFSTES). 
Two different series of numerical simulations were conducted in this parametric study. In SERIES 1 (Table 3 and Fig. 10), all the columns had exactly the same quantity of steel split into the two profiles (inner + outer) - i.e. same total steel cross-sectional area - , while in SERIES 2 (Table 4 and Fig. 11) all the columns had the same axial load-bearing capacity at room temperature.

For comparison purposes, the CFDST sections in SERIES 1 were studied twice, with and without concrete inside the inner steel tube (i.e. double-tube and double-skin configurations, CFDST-XXa and CFDST-XXb, respectively).

The length of the columns was $3240 \mathrm{~mm}$ and pinned-pinned boundary conditions were used in all the numerical simulations, resulting in a relative slenderness of 0.5 in the case of the reference CFST column. The steel grade of all the outer tubes was S355, while C30 concrete was used for the encasement. A concentric axial load of $1408.80 \mathrm{kN}$ was applied to all the columns, corresponding to a $30 \%$ of the maximum capacity of the CFST column at room temperature.

\subsection{Comparison between different cross-sectional geometries}

The different sections studied in SERIES 1 (same steel usage), can be seen in Fig. 10, while their geometrical and mechanical features are summarized in Table 3. In the first instance, only columns using normal strength steel S355 at the inner profiles are compared, in order to study the effect of the geometry alone. It is worth noting that the differences in room temperature load bearing capacity, for those columns using S355 steel (CFST, CFDST-01a, CFST-HEB-01 and CFSTES-01 in Table 3), ranged between a 3\% and a 5\%, therefore the four columns would perform in a similar way at room temperature, while showing identical external appearance and using the same amount of steel. Only in the case of the double-skin column (CFDST-01b) this is not accomplished, as this section presents less amount of concrete. 
The four types of columns were analysed by means of the previously described numerical model. The results of the simulations are shown in Fig. 12 in the form of axial displacement versus time curves, measured at the top end of the columns. Besides, the values of the different failure times are given in Table 3. As it can be seen, the reference CFST column presented a very limited fire resistance of only 28 minutes. The CFSTES solution lengthened the failure time slightly, up to 36 minutes (CFSTES-01). In turn, with the CFST-HEB solution, using an inner HEB160 profile, the fire resistance of the column was increased up to 47 minutes (CFSTHEB-01). Finally, if the steel tube was split into two tubes, generating the CFDST column with the ticker tube in the inner part of the section, the fire resistance was significantly improved to 77 minutes, if the inner tube was infilled with concrete (i.e. double-tube, CFDST-01a). Therefore, it is proved that a good strategy for enhancing the fire resistance of traditional CFST columns is to split the outer steel tube into two tubes, using most of the steel in the inner profile, which is thermally protected by the concrete encasement, delaying its degradation at elevated temperatures. Note that these solutions make use of the same amount of steel and concrete, whilst maintaining the same external dimensions of the columns. In the case of not using concrete inside the inner tube (i.e. double-skin, CFDST-01b), there is still an improvement in terms of fire resistance to 63 minutes, although not as significant as that obtained with the double-tube solution.

It may result interesting to study the evolution of the load sharing among the different components of the cross-section, in order to provide some insight to the fire performance of the composite columns studied in this paper. Fig. 13 shows the distribution of the axial load ratio along the fire exposure time for different sections (CFST, CFDST-01a, CFST-HEB-01 and CFSTES-01 in Table 3). A common observation in the four solutions is that during the first minutes of fire exposure, the load share of the outer steel tube rapidly increases as it expands and separates from the rest of components, until it sustains the total applied load. After a certain 
period of time, the outer steel tube starts to degrade due to its fast temperature rise, moment when the load is transferred to the inner components of the section, which progressively increase their load share as the outer tube continues losing capacity. In the case of the conventional CFST section, only the concrete core contributes to sustain the load after the steel tube yielding, although during a very limited amount of time. Nevertheless, in the case of the rest of sections (CFDST, CFST-HEB or CFSTES), it is observed an important contribution of the inner profiles, which progressively increase their load share and lengthen the fire endurance of the section. It can be seen that, while the contribution of the concrete encasement is quite limited - not higher than $30 \%$ in the best case -, that of the inner profiles is quite significant, reaching $80 \%$ of the load ratio in the case of the CFDST or CFST-HEB columns. Therefore, this comparison proves that it is useful to replace some of the steel used at the outer tube with inner steel profiles, which become thermally protected by the concrete encasement and therefore can retain their load-bearing capacity during a longer period of time.

A comparison in terms of the temperature field of the different cross-sections studied in this first series is given in Fig. 14, after 90 minutes of fire exposure. It can be seen that for the CFST section, the distribution of the material is not efficient, as all the steel is located at the exposed surface, where the temperature is higher, about $970{ }^{\circ} \mathrm{C}$ after 90 minutes (in fact, for such a temperature the steel cannot retain any strength or stiffness). In the case of the other three sections, the inner profiles are protected by the concrete layer and therefore subjected to lower temperatures, what means that an important amount of steel can still contribute to sustain the load after a certain period of time, which is what gives these sections the enhancement in fire resistance as compared with the original CFST.

While the temperatures of the outer steel tube are the same for all the configurations studied (about $970{ }^{\circ} \mathrm{C}$ at 90 minutes and coincident to that of the reference CFST), the temperatures of the inner steel profiles vary. As can be seen in Fig. 14, the temperatures at the 
relevant points of the HEB section (corner of flange, centre of flange and centre of web) are always higher than those at inner steel tube of the CFDST or inner steel core of the CFSTES, due to the non-uniform thickness of the concrete cover. In fact, the temperatures of the inner steel tube for the case of the CFDST column are comparable to those measured at the coldest point of the HEB profile, i.e. in the centre of its web. The lower temperatures of the inner profile are found for the CFSTES column as expected, since the diameter of the core is of a reduced dimension and therefore the thickness of the concrete ring is wider. Nevertheless, its reduced diameter makes the slenderness of the inner core far too high to sustain the load on its own, and thus the CFSTES column (36 min) failed before the CFST-HEB column (47 minutes) or the CFDST column (77 minutes), despite the temperature of its inner profile being lower. The relative slenderness of the inner profiles can be calculated as a reference, being $\bar{\lambda}=0.95$ for a CHS $139.7 \times 13.71 \mathrm{~mm}$ (inner profile of CFDST-01), $\bar{\lambda}=1.05$ for an HEB160 (inner profile of CFST-HEB-01) and $\bar{\lambda}=2.04$ for a $\phi 83.12 \mathrm{~mm}$ steel core (inner profile of CFSTES-01), what explains the reduced fire resistance times reached by the series of CFSTES columns.

\subsection{Influence of the steel grade of the inner profiles}

The fire resistance of these innovative solutions can be further increased by using high strength steels (HSS) for the inner profiles. In the first series of simulations, SERIES 1 (Table 3 and Fig. 10), the yield strength of the inner profiles was varied for each of the cross-sections studied, using steel grades S460, S690 and S960, alongside the already used S355. The results obtained by upgrading the steel grade of the inner profiles to S460, compared to the previous simulations using S355 steel, can be seen in Fig. 15a for all the geometries studied. For the CFSTES column, only a marginal increment was found. However, in the case of the CFSTHEB, the fire resistance increased from 47 to 57 minutes (CFST-HEB-01 vs CFST-HEB-02). Finally, for the CFDST columns, a noticeable increase from 77 to 94 minutes was obtained in 
the case of the double-tube solution (CFDST-01a vs CFDST-02a), and from 63 to 77 for the double-skin solution (CFDST-01b vs CFDST-02b).

If the grade of the inner steel tubes is further increased to S690 or S960, the enhancement of the fire resistance is more noticeable. A general comparison is shown in Fig. 15b for S960 steel in the inner profiles, superimposed with the results for the reference S355. Fire resistance times of 120 and 141 minutes are reached for the case of the double-tube column (CFDST-03a and CFDST-04a), or 71 and 86 for the CFST-HEB column (CFST-HEB-03 and CFST-HEB04). In the case of the CFSTES column, no benefit is observed by increasing the strength of the embedded steel core, as due to its reduced diameter, its slenderness is too high $(\bar{\lambda}=2.04)$ and hence it is unable to sustain the load on its own after the rest of the section has degraded.

Additionally, it can be seen in Fig. 16 that a significant enhancement is obtained for the CFDST columns by using higher steel grades, for both configurations, double-skin and doubletube. It is also worth noting that, for all the steel grades, the double-tube configuration provides a higher fire resistance than the double-skin one.

It should be noted that, apart from increasing the fire resistance of the columns in the case of CFDST and CFST-HEB, their maximum capacity at room temperature was significantly increased by using a higher steel grade for the inner profiles (see Table 3), while maintaining the external dimensions. This increase in load-bearing capacity can reach a $45 \%$ in the case of using S960 steel on a CFDST section (CFDST-04a). Therefore, as this numerical study proves, by using HSS for the inner profiles; both the load-bearing capacity of the columns at room temperature and their fire resistance can be enhanced at the same time. However, it is worth noting that the load applied to all the columns in SERIES 1 was constant and thus the corresponding reduction on the axial load level for increasing steel grades should be taken into account in the design. 


\subsection{Comparison for the same room temperature capacity}

A second series of numerical simulations was performed (SERIES 2) by equalling all the columns in terms of axial load-bearing capacity at room temperature, using the different section types and steel grades of the previous analysis. The different sections studied in this second series can be seen in Fig. 11, while their geometrical and mechanical features are summarized in Table 4. The value of the design axial buckling load of the columns at room temperature $\left(N_{b, R d}\right)$ has been calculated by using the method in EN1994-1-1 [48]. Although this calculation method is only valid for CFST columns, it has been applied in this paper to CFDST, CFSTHEB and CFSTES columns, adopting these assumptions: a) buckling curve "a" is used for all the cases, as for an unreinforced CFST column (which is the case of the reference column), b) no confinement is considered, c) the material safety factors are equalled to unity.

With these assumptions, the dimensions of the inner profiles of the different types of columns studied have been varied so as to obtain the same axial buckling load at room temperature as that of the reference CFST column. It should be noted that for the case of the CFST-HEB columns, it was not possible to obtain exactly the same value of the load as the reference one, since commercial dimensions were used for the HEB profiles. However, the closest available HEB sections were taken, with deviations in terms of maximum load of only 0.96 to 1.05 with regard to the CFST section (see Table 4).

It is worth noting in the referred table that the amount of steel needed in the section decreases as the steel grade is increased, up to a 0.68 in the case of the CFDST column (CFDST08) as compared with the reference CFST column. This means that the same load-bearing capacity at room temperature can be reached with important material savings when using HSS in the inner profiles, although the differences in cost of the higher steel grades should be also evaluated. 
The results obtained in this new series of numerical simulations can be seen in Fig. 17 for the CFDST sections in particular and in Fig. 18 for all the geometries studied. As it can be seen, if the steel grade is improved whilst maintaining the same room temperature capacity of the columns, the enhancement in fire resistance is not so clear, as the dimensions of the inner profiles result smaller as their yield strength is increased. For the case of CFDST columns, Fig. 17, the higher fire resistance is obtained with the solution using S355 steel, followed by S690, S960 and finally S460. The same effect occurs for the other two types of sections studied, although with a different sequence. It can be observed that in fact, for CFSTES columns, the fire resistance time can become even lower than that of the reference CFST column for the higher steel grade (26 minutes versus 28 minutes comparing case CFSTES-08 with the reference case CFST in Table 4 and Fig. 18b). In any case, the columns with higher steel strengths make use of a smaller inner section and therefore less amount of steel, with the consequent material savings. Therefore, if the room temperature capacity is taken as a reference, different factors should be taken into account when deciding on what the optimal solution should be.

\section{DESIGN STRATEGY FOR IMPROVED FIRE RESISTANCE}

It has been shown that a good strategy for enhancing the fire resistance of traditional CFST columns is to split the outer steel tube into two profiles using most of the steel in the inner profile, thermally protected by the concrete encasement, which delays its degradation at elevated temperatures. This strategy can be thought as an alternative to applying external protection with intumescent coatings or paintings. By splitting the outer tube into two profiles, moving most of the amount of steel towards the inner part of the section, the resisting profile results "internally" protected by the surrounding concrete and, what is more, its capacity at elevated temperature can be improved by increasing the inner steel grade, without changing the external appearance of the column as well as being maintenance free. 
If the steel grade of the inner profiles is increased by using HSS, for the same steel usage, both the load-bearing capacity of the columns at room temperature and their fire resistance are enhanced, although it must be taken into account that, for a certain value of the applied axial load, the utilization level decreases when increasing the steel grade. Moreover, the differences in cost related to using HSS at the inner profiles should be evaluated.

If the load-bearing capacity of the column at room temperature is to be maintained, the enhancement in fire resistance becomes not so clear when the steel grade is improved, as the dimensions of the inner profiles result smaller for increasing yield strengths and thus present a higher slenderness. However, important material savings may be obtained when using HSS at the inner profiles with a reduction in the steel area.

Therefore, a good strategy for enhancing the fire resistance of these composite columns is to improve the steel grade of the inner profile without reducing the total steel area, although one must bear in mind that this changes the utilization level and also increases the material cost. If the aim of the designer is to maintain the utilization level while improving the steel grade i.e. by reducing the area of the inner profile -, the fire performance of the column may be affected negatively, as the slenderness of the inner profile increases.

\section{SUMMARY AND CONCLUSIONS}

This paper presented a numerical study for investigating the fire behaviour of innovative steel-concrete composite columns, i.e. CFST columns using inner steel profiles such as CHS, HEB or embedded steel cores. The objective of this study was to develop strategies for enhancing the fire resistance of traditional CFST columns by using inner steel profiles. A finite element model was developed, which was able to represent with good accuracy the behaviour of the different types of sections studied. Additionally, the convenience of using HSS at the inner profiles as a way of increasing the fire endurance was assessed, employing steel grades S460, S690 and S960. By means of the developed numerical model, parametric studies were 
conducted, in order to analyse the fire behaviour of the different types of sections and the effect of increasing the steel grade of the inner profiles. Two series of numerical simulations were performed: in the first series of simulations, all the column specimens made use of the same total amount of steel, while in the second series the columns were compared for the same room temperature capacity.

The more efficient solution of those compared in this study was - with a significant difference - to use a double-tube configuration, followed by the solution using an inner HEB profile. Embedding a massive steel core did not show to provide a significant enhancement in terms of fire resistance when using the same amount of steel. It was also found out that the fire performance of these columns might be significantly enhanced by using HSS in the inner profiles.

To sum up, the presented work revealed good practices for improving the fire performance of CFST columns through the use of inner steel profiles made of HSS. These strategies offer an alternative to applying intumescent coatings, with better external appearance, zero maintenance, same steel usage and thus similar cost. This work may be completed in the future by means of a more extended study which takes into account on the economic factors.

\section{ACKNOWLEDGEMENTS}

The authors gratefully acknowledge the financial support given by Universitat Politècnica de València for providing the funding for the first author's stay as a visiting fellow at the School of Engineering of the University of Bradford.

The authors would also like to express their sincere gratitude to the Spanish "Ministerio de Economía y Competitividad" for the help provided through the Project BIA2012-33144, from which some of the experimental results have been used in this work for validation of the numerical model. 


\section{REFERENCES}

[1] Romero ML, Moliner V, Espinos A, Ibañez C, Hospitaler A. Fire behavior of axially loaded slender high strength concrete-filled tubular columns, Journal of Constructional Steel Research 2011; 67:1953-1965.

[2] Moliner V, Espinos A, Romero ML, Hospitaler A. 2013. Fire behavior of eccentrically loaded slender high strength concrete-filled tubular columns. Journal of Constructional Steel Research 2013; 83:137-146.

[3] Espinos A, Romero ML, Serra E, Hospitaler A. Circular and square slender concrete-filled tubular columns under large eccentricities and fire. Journal of Constructional Steel Research 2015; 110:90-100.

[4] Espinos A, Romero ML, Serra E, Hospitaler A. Experimental investigation on the fire behaviour of rectangular and elliptical slender concrete-filled tubular columns. ThinWalled Structures 2015; 93:137-48.

[5] Zhao XL, Han LH. Double skin composite construction. Progress in Structural Engineering and Materials 2006; 8(3):93-102.

[6] Han LH, Li W, Bjorhovde R. Developments and advanced applications of concrete-filled steel tubular (CFST) structures: Members. Journal of Constructional Steel Research 2014; 100:211-28.

[7] Elchalakani M, Zhao XL, Grzebieta R. Tests on concrete filled double-skin (CHS outer and SHS inner) composite short columns under axial compression. Thin-Walled Structures $2002 ; 40(5): 415-441$.

[8] Huang H, Han LH, Tao Z, Zhao XL. 2010. Analytical behaviour of concrete-filled double skin steel tubular (CFDST) stub columns. Journal of Constructional Steel Research 66(4):542-555. 
[9] Liew JYR, Xiong DX. 2011. Experimental investigation on tubular columns infilled with ultra-high strength concrete. Tubular Structures XIII Boca Raton: Crc Press-Taylor \& Francis Group: 637-645.

[10] Tao Z, Han LH, Zhao XL. 2004. Behaviour of concrete-filled double skin (CHS inner and CHS outer) steel tubular stub columns and beam-columns. Journal of Constructional Steel Research 60(8):1129-1158.

[11] Tao Z, Han LH. 2006. Behaviour of concrete-filled double skin rectangular steel tubular beam-columns. Journal of Constructional Steel Research 62(7):631-646.

[12] Tao Z, Wang ZB, Tu Q. 2013. Finite element modelling of concrete-filled steel stub columns under axial compression. Journal of Constructional Steel Research 89:212-131.

[13] Zhao XL, Tong LW, Wang XY. 2010. CFDST stub columns subjected to large deformation axial loading. Engineering Structures 32(3):692-703.

[14] Lu H, Han LH, Zhao XL. Fire performance of self-consolidating concrete filled double skin steel tubular columns: Experiments. Fire Safety Journal 2010; 45(2):106-115.

[15] Lu H, Zhao XL, Han LH. FE modelling and fire resistance design of concrete filled double skin tubular columns. Journal of Constructional Steel Research 2011; 67:1733-48.

[16] Lu H, Zhao XL, Han LH. Testing of self-consolidating concrete-filled double skin tubular stub columns exposed to fire. Journal of Constructional Steel Research 2010; 66:1069-80.

[17] Romero ML, Espinos A, Portoles JM, Hospitaler A, Ibañez C. Slender double-tube ultrahigh strength concrete-filled tubular columns under ambient temperature and fire. Engineering Structures 2015; 99:536-45.

[18] Espinos A, Romero ML, Hospitaler A, Pascual AM, Albero V. Advanced materials for concrete-filled tubular columns and connections. Structures 2015; 4:105-13. 
[19] Chu TB. Hollow steel section columns filled with self-compacting concrete under ordinary and fire conditions. PhD thesis. University of Liege, Belgium; 2009.

[20] Dotreppe JC, Chu TB, Franssen JM. Steel hollow columns filled with self-compacting concrete under fire conditions. Proceedings of the 3rd Congress of the International Federation for Structural Concrete (FIB) and PCI Conference. Washington DC, USA; 2010.

[21] Chu TB, Gernay T, Dotreppe JC, Franssen, JM. Steel hollow columns with an internal profile filled with self-compacting concrete under fire conditions. Proceeding of the Romanian Academy. Series A, Mathematics, Physics, Technical Sciences, Information Science. Bucarest, Romania.

[22] Chu TB, Dotreppe JC, Franssen, JM. Heat transfer and structural response modelling of concrete filled steel hollow section columns. Proceedings of the International Conference on Advances in Computational Mechanics (ACOME). Hochiminh, Vietnam; 2012.

[23] Neuenschwander M, Knobloch M, Fontana M. Fire tests of concrete-filled circular hollow section columns with solid steel core. Proceedings of the VII International Composite Construction. Palm Cove Cairns, Queensland, Australia; 2013.

[24] Neuenschwander M, Knobloch M, Fontana M. Fire behavior of concrete filled circular hollow section columns with massive steel core. Proceedings of the International Colloquium Stability and Ductility of Steel Structures SDSS. Rio de Janeiro, Brazil; 2010.

[25] Schaumann P, Kleiboemer I. Experimental investigations on the thermal and mechanical behaviour of composite columns with massive steel core in fire. Proceedings of the 1 st International Fire Safety Symposium (IFireSS). Coimbra, Portugal; 2015.

[26] Schaumann P, Kleiboemer I. Zum Trag- und Erwärmungsverhalten von Verbundstützen mit massivem Stahlkern im Brandfall. Bautechnik 2015; 92:330-334. 
[27] Hamme U, Schaumann P. Rechnerische Analyse von Walzeigenspannungen. Stahlbau $1987 ; 56: 328-334$.

[28] Qiang X. Behaviour of high strength steel endplate connections in fire and after fire. Doctoral thesis. Delft, Netherlands: Delft Academic Press; 2013.

[29] Tondini N, Hoang VL, Demonceau JF, Franssen JM. Experimental and numerical investigation of high-strength steel circular columns subjected to fire. Journal of Constructional Steel Research 2013; 80:57-81.

[30] CEN. EN 1993-1-12, Eurocode 3: Design of steel structures, Part 1.12: Additional rules for the extension of EN 1993 up to steel grades S 700. Brussels, Belgium: Comité Européen de Normalisation, 2007.

[31] CEN. EN 1993-1-2, Eurocode 3: Design of steel structures, Part 1.2: General rules Structural fire design. Brussels, Belgium: Comité Européen de Normalisation, 2005.

[32] Lange J, Wohlfeil N. Examination of the mechanical properties of the microalloyed grain refined steel S460 at elevated temperatures. Bautechnik 2007; 84:711-720.

[33] Schneider R, Lange J. Constitutive equations of structural steel S460 at high temperatures. In: Nordic Steel Construction Conference 2009: 204-211. Sweden; 2009.

[34] Outinen J. Mechanical properties of structural steels at high temperatures and after cooling down. Laboratory of Steel Structures, Helsinki University of Technology. Helsinki, Finland; 2007.

[35] Chen J, Young B, Uy B. Behaviour of high strength structural steel at elevated temperatures. Journal of Structural Engineering 2006; 132:1948-1954.

[36] Chen J, Young B. Design of high strength steel columns at elevated temperatures. Journal of Constructional Steel Research 2008; 64:689-703. 
[37] Chiew SP, Zhao MS, Lee CK. Mechanical properties of heat-treated high strength steel under fire/post-fire conditions. Journal of Constructional Steel Research 2014; 98:12-19.

[38] Qiang X, Bijlaard F, Kolstein H. Dependence of mechanical properties of high strength steel S690 on elevated temperatures. Construction and Building Materials 2012; 30:73-79.

[39] Qiang X, Bijlaard F, Kolstein H. Deterioration of mechanical properties on high strength structural steel S460N under transient state fire condition. Materials and Design 2012; 40:521-527.

[40] Qiang X, Bijlaard F, Kolstein H. Post-fire mechanical properties of high strength structural steels S460 and S690. Engineering Structures 2012; 35:1-10.

[41] Qiang X, Bijlaard F, Kolstein H. Elevated temperature mechanical properties of high strength structural steel S460N: Experimental study and recommendations for fire resistance design. Fire Safety Journal 2013; 55:15-21.

[42] Qiang X, Bijlaard F, Kolstein H. Post-fire performance of very high strength steel S960. Journal of Constructional Steel Research 2013; 80:235-42.

[43] Choi IR, Chung KS, Kim DH. Thermal and mechanical properties of high-strength structural steel HSA800 at elevated temperatures. Materials and Design 2014; 63:544-51.

[44] Zhao XL, Heidarpour A, Gardner L. Recent developments in high-strength and stainless steel tubular members and connections. Steel Construction 2014; 7:65-72.

[45] Espinos A, Romero ML, Hospitaler A. 2010. Advanced model for predicting the fire response of concrete filled tubular columns. Journal of Constructional Steel Research 66(8-9):1030-1046.

[46] ABAQUS. 2014. ABAQUS/Standard Version 6.14 User's Manual: Volumes I-III. Pawtucket, Rhode Island: Hibbitt, Karlsson \& Sorensen, Inc. 
Espinos A, Romero ML, Lam D. Fire performance of innovative steel-concrete composite columns using high strength steels. doi: 10.1016/j.tws.2016.04.014

[47] CEN. EN 1994-1-2, Eurocode 4: Design of composite steel and concrete structures. Part 1.2: General rules - Structural fire design. Brussels, Belgium: Comité Européen de Normalisation; 2005.

[48] CEN. EN 1994-1-1, Eurocode 4: Design of composite steel and concrete structures. Part 1.1: General rules and rules for buildings. Brussels, Belgium: Comité Européen de Normalisation; 2004.

[49] CEN. EN 1992-1-2, Eurocode 2: Design of concrete structures, Part 1.2: General rules Structural fire design. Brussels, Belgium: Comité Européen de Normalisation, 2004. 
Espinos A, Romero ML, Lam D. Fire performance of innovative steel-concrete composite columns using high strength steels. doi: 10.1016/j.tws.2016.04.014

a)

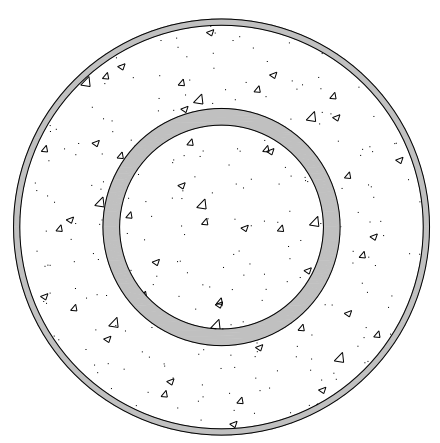

SECTION TYPE I

(CFDST) b)

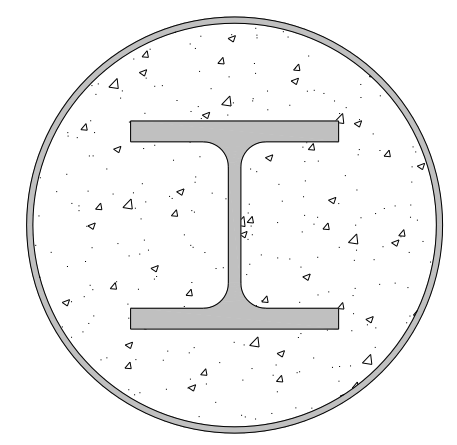

SECTION TYPE II

(CFST-HEB) c)

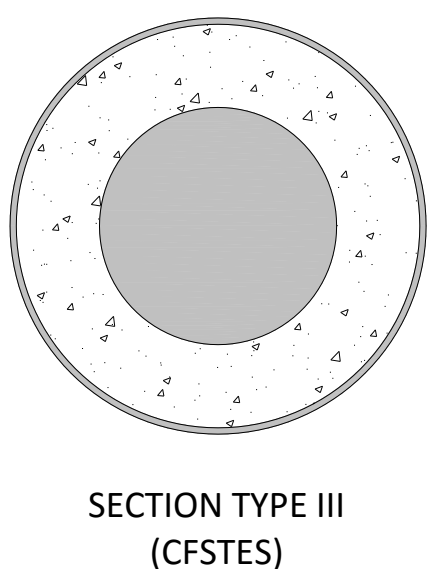

Fig. 1. Types of composite sections studied in this paper. 
Espinos A, Romero ML, Lam D. Fire performance of innovative steel-concrete composite columns using high strength steels. doi: 10.1016/j.tws.2016.04.014
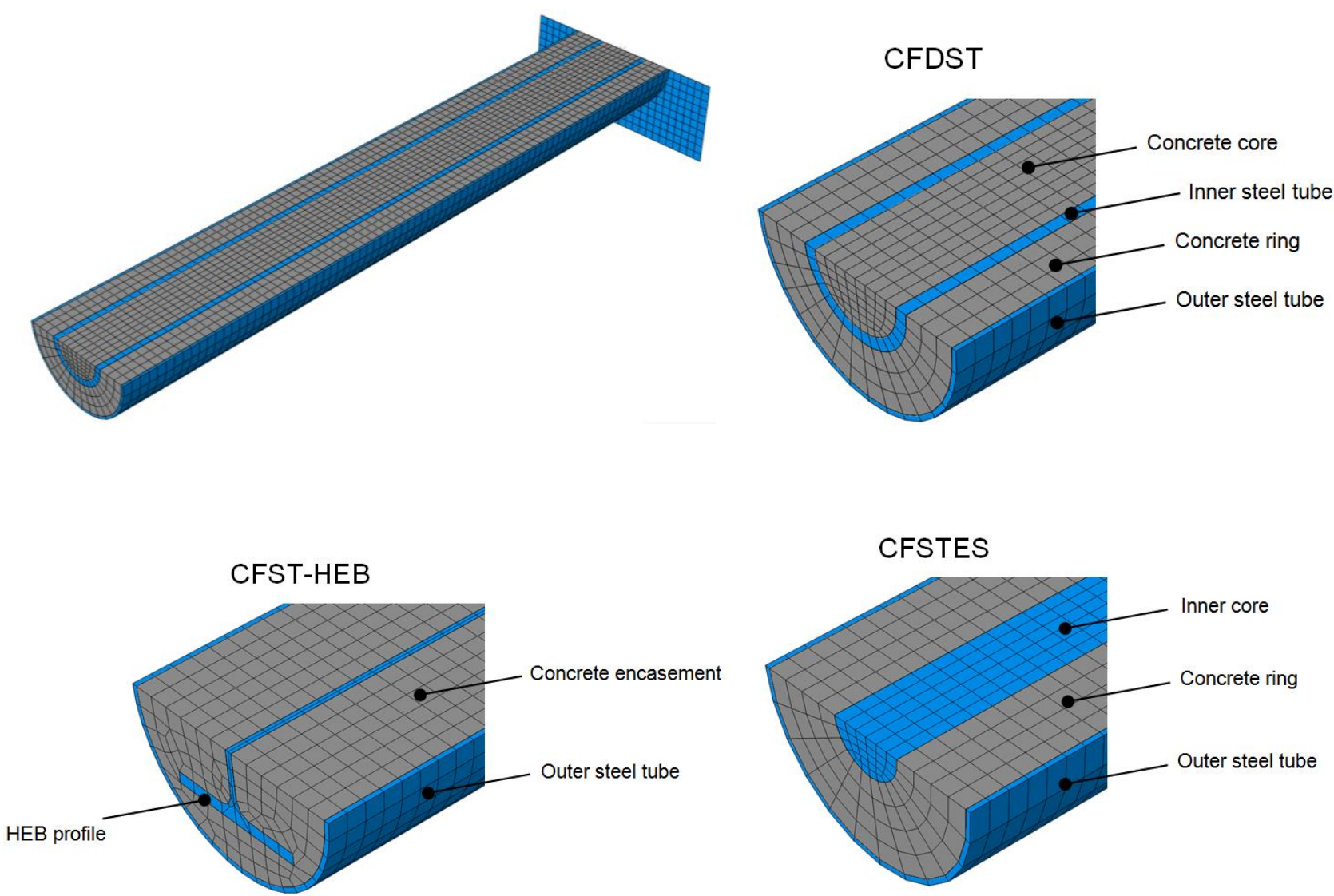

Fig. 2. Finite element mesh for the different type of columns analysed. 
Espinos A, Romero ML, Lam D. Fire performance of innovative steel-concrete composite columns using high strength steels. doi: 10.1016/j.tws.2016.04.014

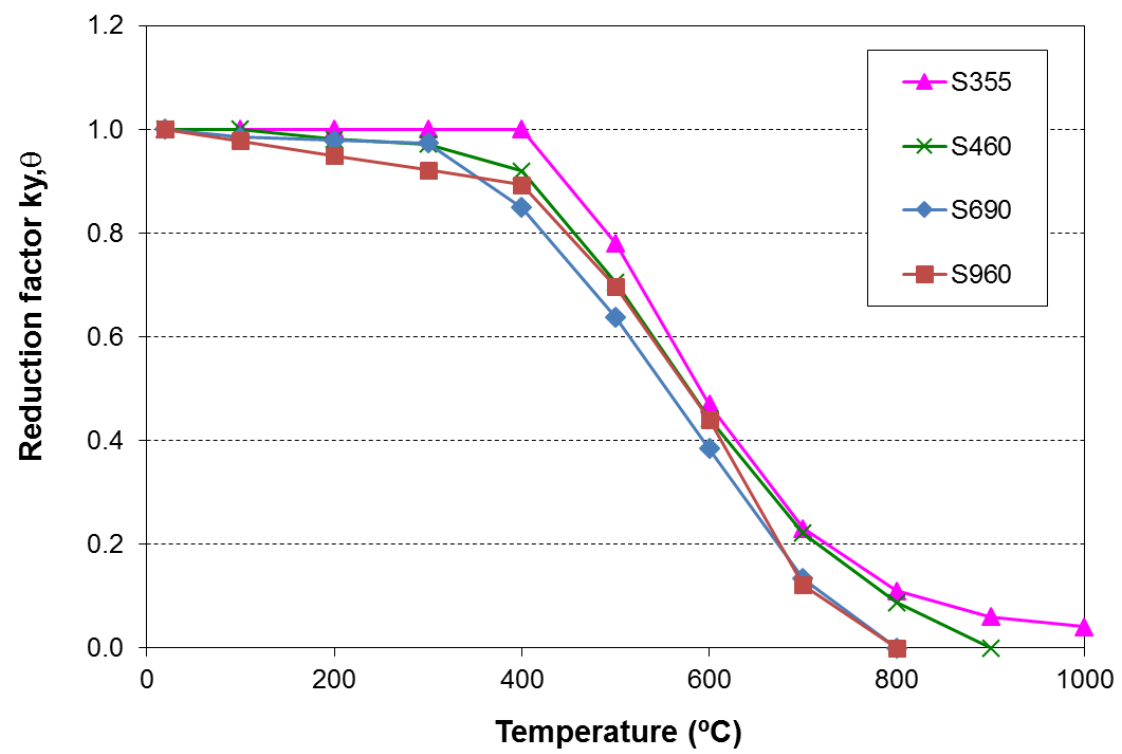

Fig. 3. Yield strength reduction factors at elevated temperatures for HSS from Qiang [28], as compared to S355 steel. 
Espinos A, Romero ML, Lam D. Fire performance of innovative steel-concrete composite columns using high strength steels.

a)

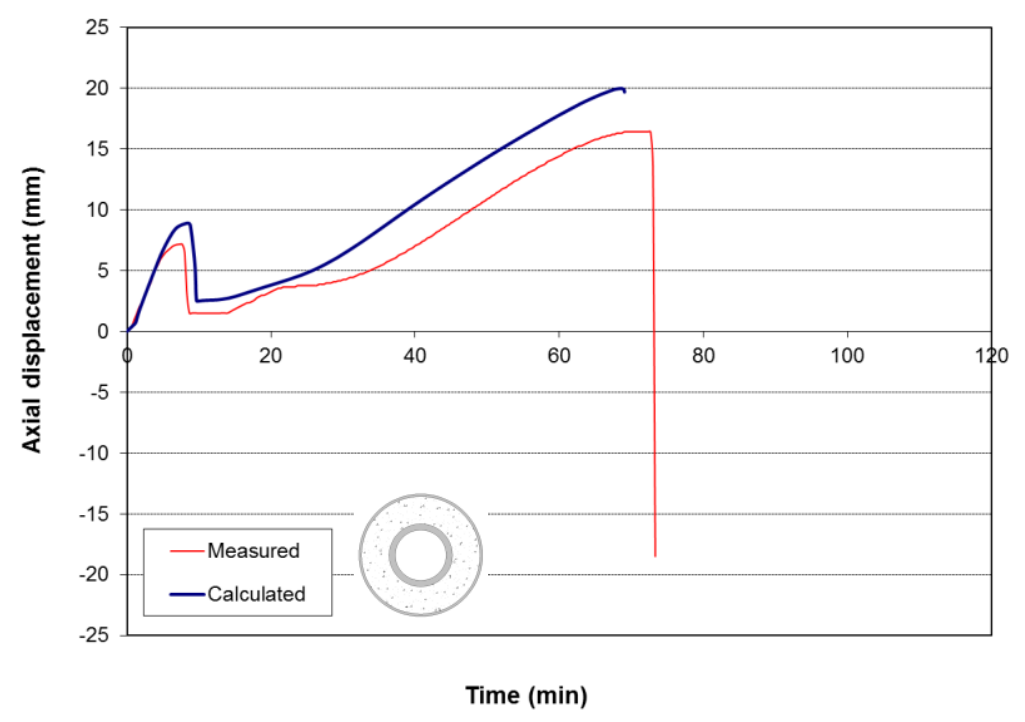

b)

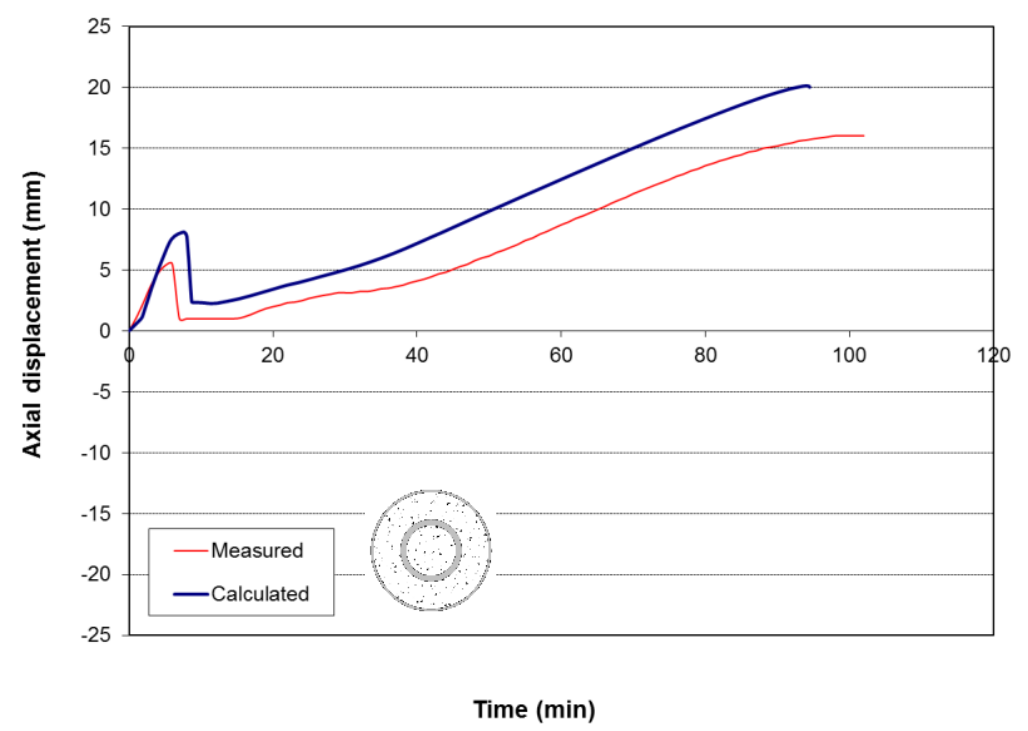

Fig. 4. Validation of the numerical model for section type I, tests from Romero et al. [17]: a) C200-3-30_C114-8-00 (double-skin); b) C200-3-30_C114-8-30 (double-tube). 
Espinos A, Romero ML, Lam D. Fire performance of innovative steel-concrete composite columns using high strength steels.

a)

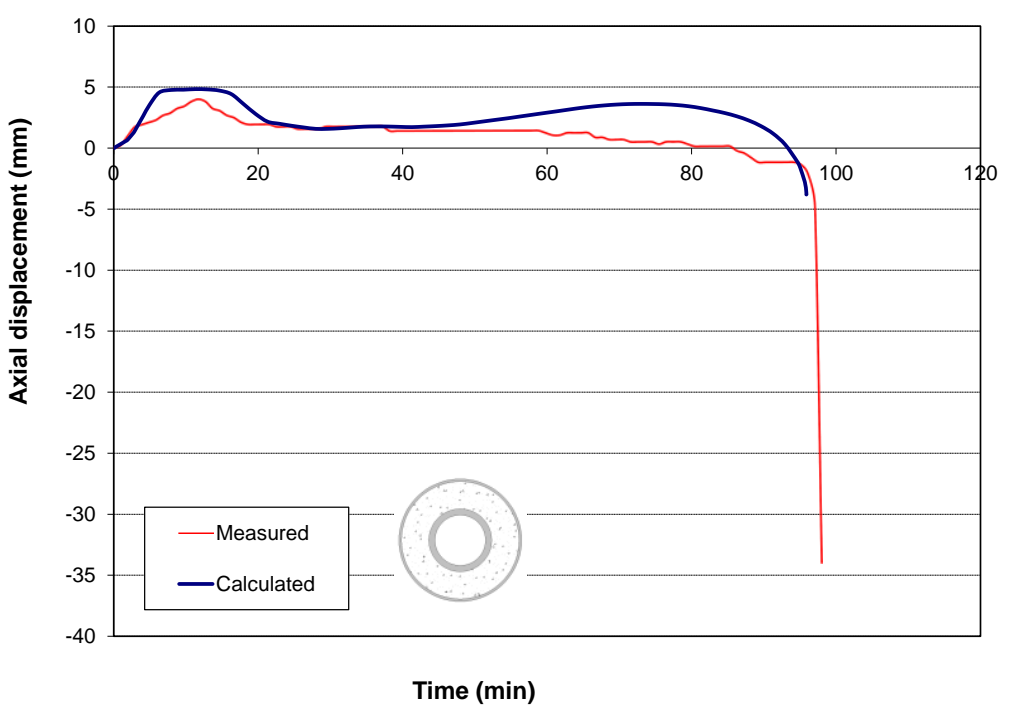

b)

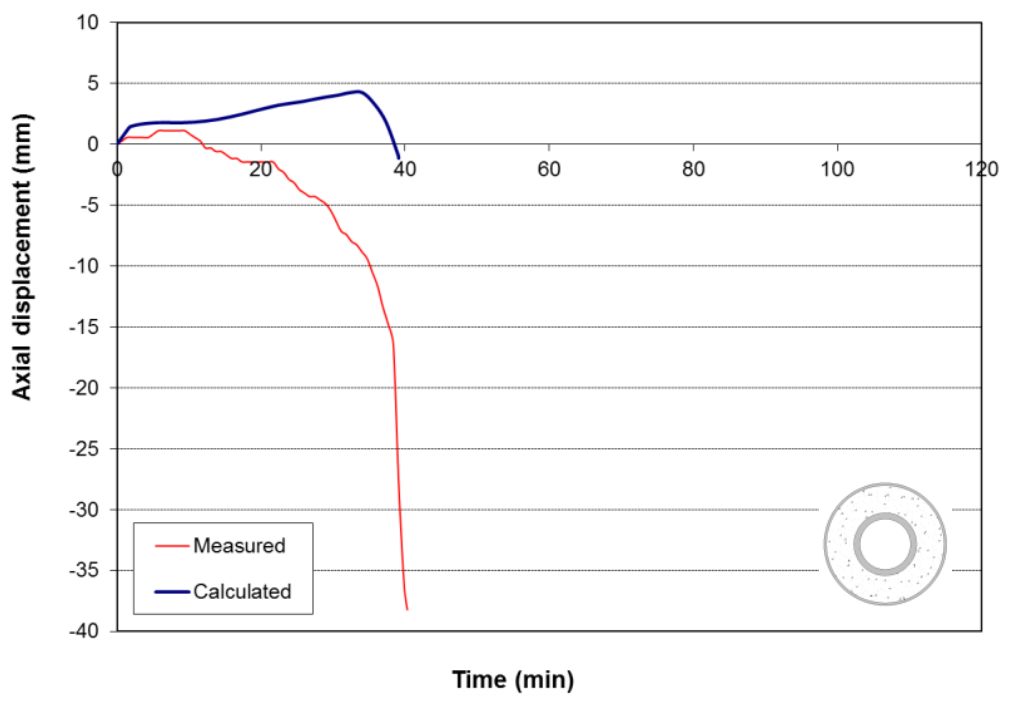

Fig. 5. Validation of the numerical model for section type I, tests from Lu et al. [14]: a) specimen $\mathrm{CC} 2$; b) specimen CC3. 
Espinos A, Romero ML, Lam D. Fire performance of innovative steel-concrete composite columns using high strength steels.

a)

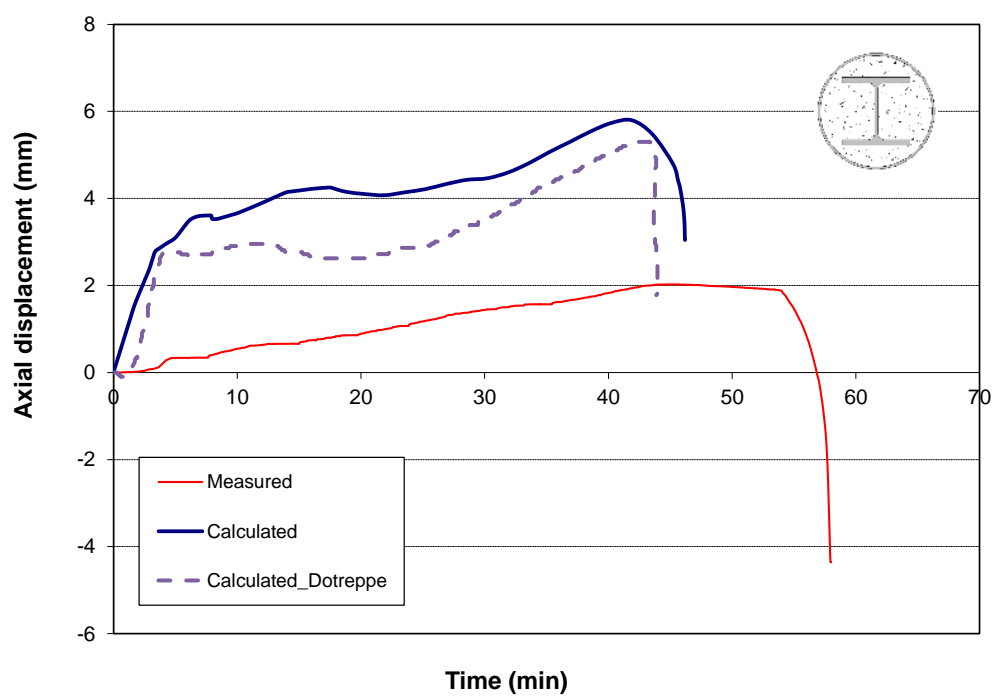

b)

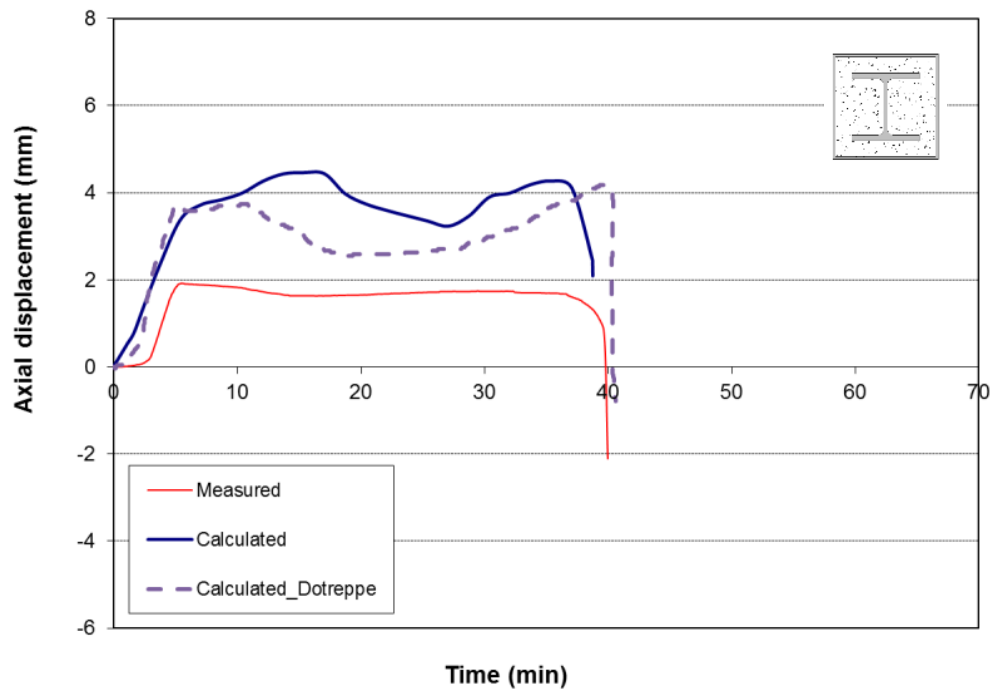

Fig. 6. Validation of the numerical model for section type II, tests from Dotreppe et al. [20]: a) specimen $3 \mathrm{~A}, \mathrm{~b}$ ) specimen $4 \mathrm{~A}$. 
a)

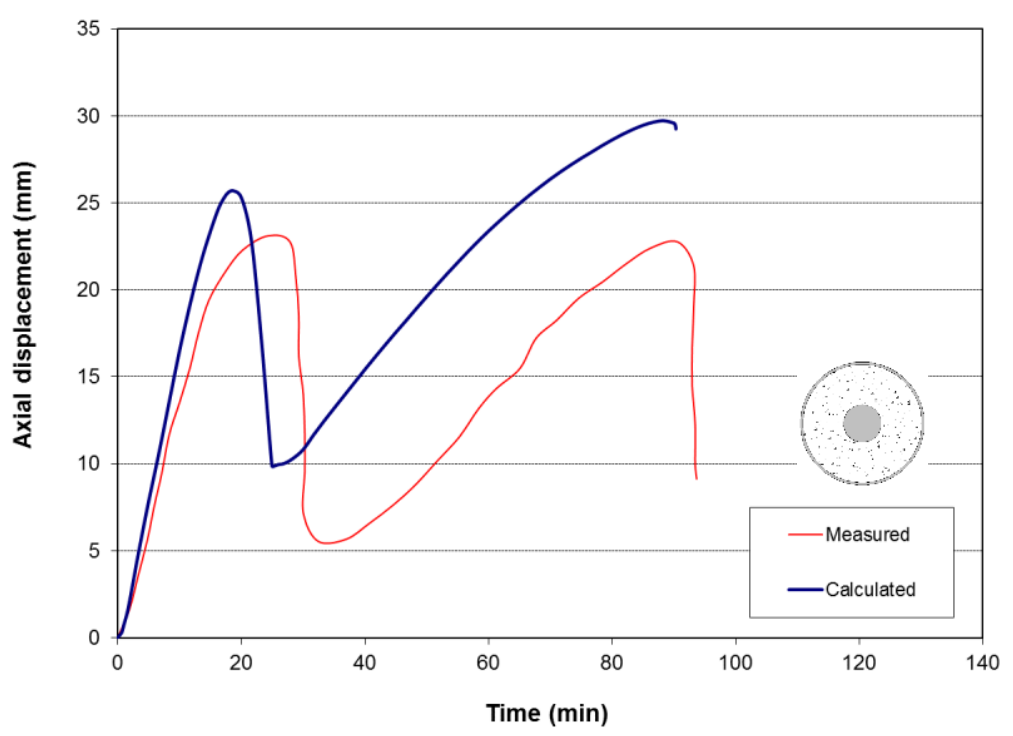

b)

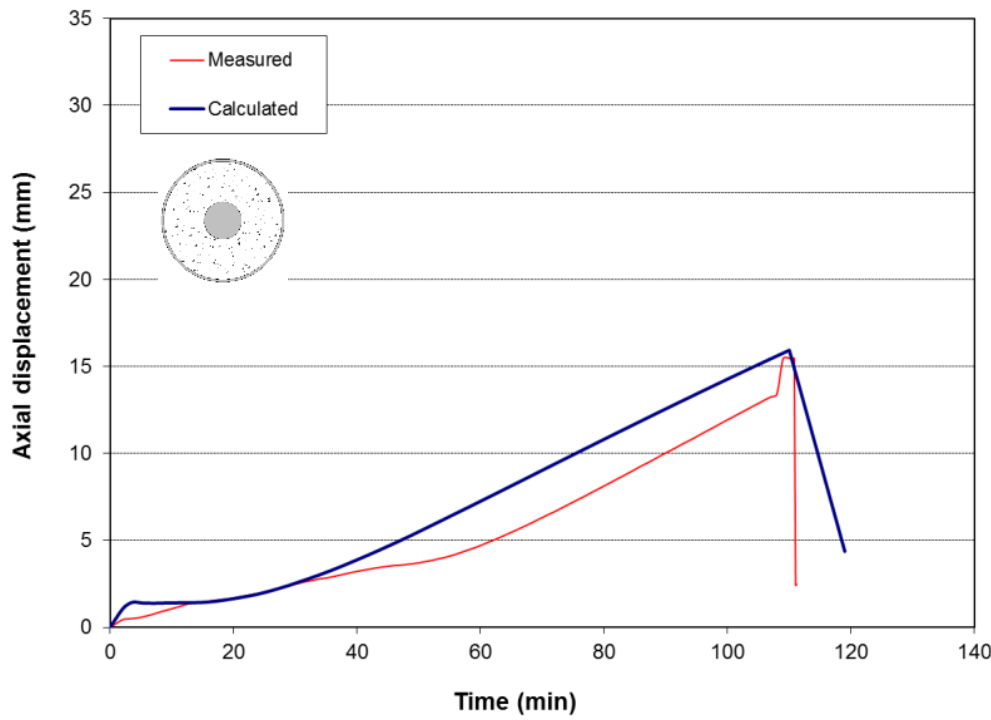

Fig. 7. Validation of the numerical model for section type III: a) specimen SP1 from Neuenschwander et al. [23], b) test from Schaumann and Kleiboemer [25]. 
Espinos A, Romero ML, Lam D. Fire performance of innovative steel-concrete composite columns using high strength steels. doi: 10.1016/j.tws.2016.04.014

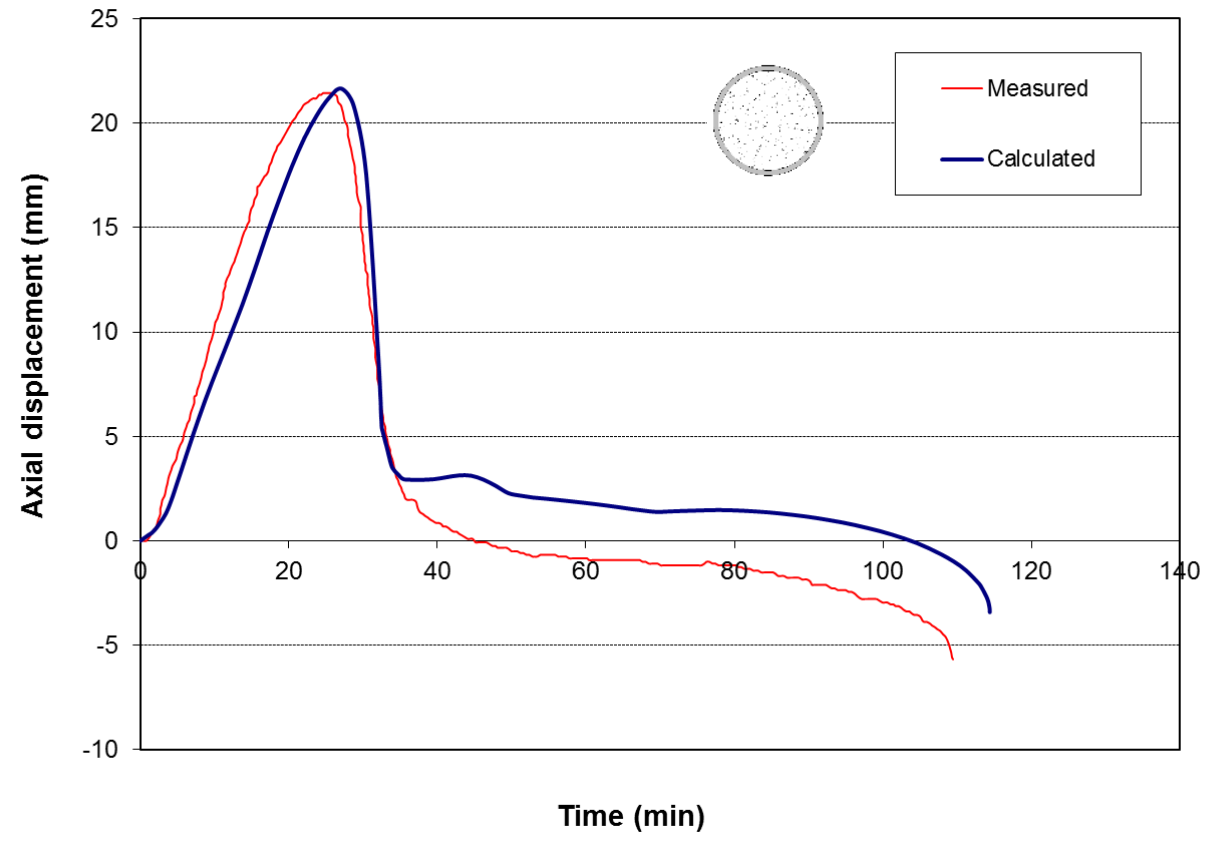

Fig. 8. Validation of the numerical model for HSS, specimen C4 from Tondini et al. [29]. 
Espinos A, Romero ML, Lam D. Fire performance of innovative steel-concrete composite columns using high strength steels. doi: 10.1016/j.tws.2016.04.014

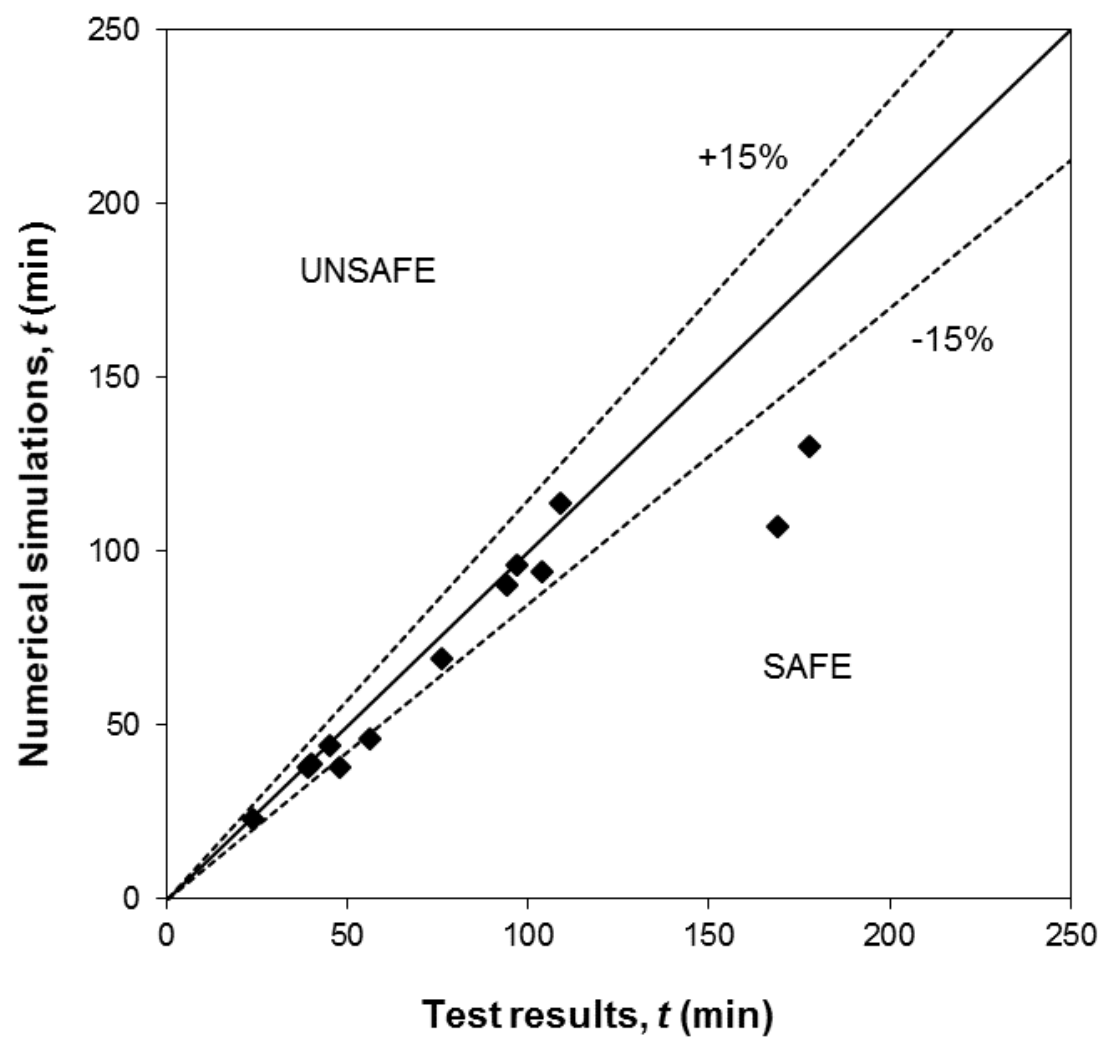

Fig. 9. Comparison between test results and numerical results, for all the columns analysed. 
Espinos A, Romero ML, Lam D. Fire performance of innovative steel-concrete composite columns using high strength steels. doi: 10.1016/j.tws.2016.04.014

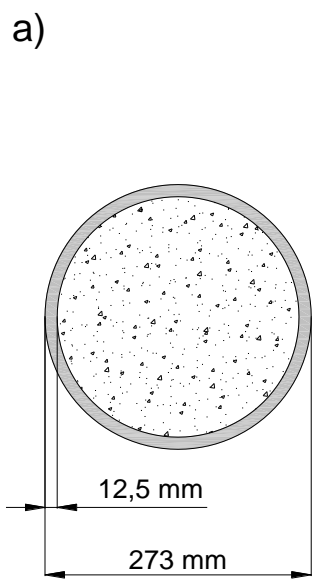

b)

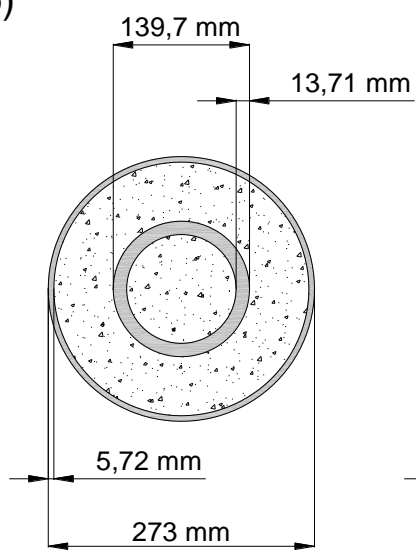

c)

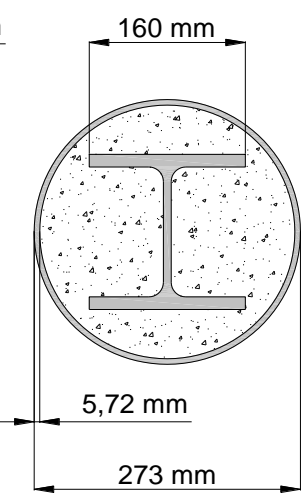

d)

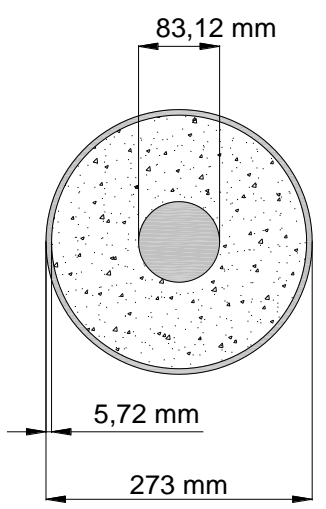

Fig. 10. Cross-sectional dimensions used in the parametric studies (SERIES 1): a) CFST; b) CFDST; c) CFST-HEB; d) CFSTES. 
a)
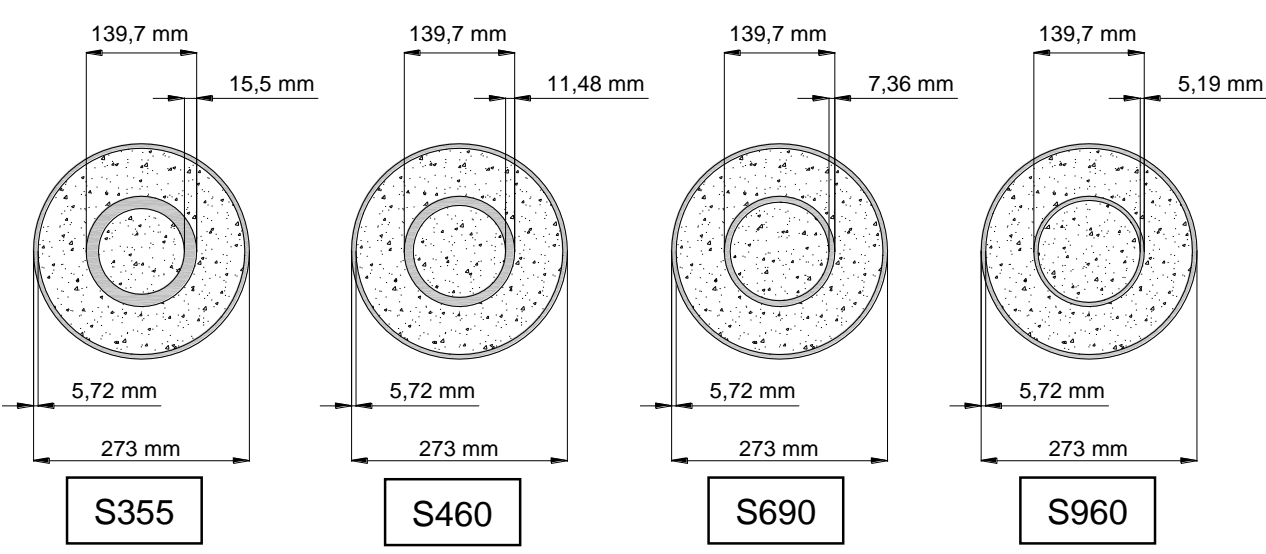

b)
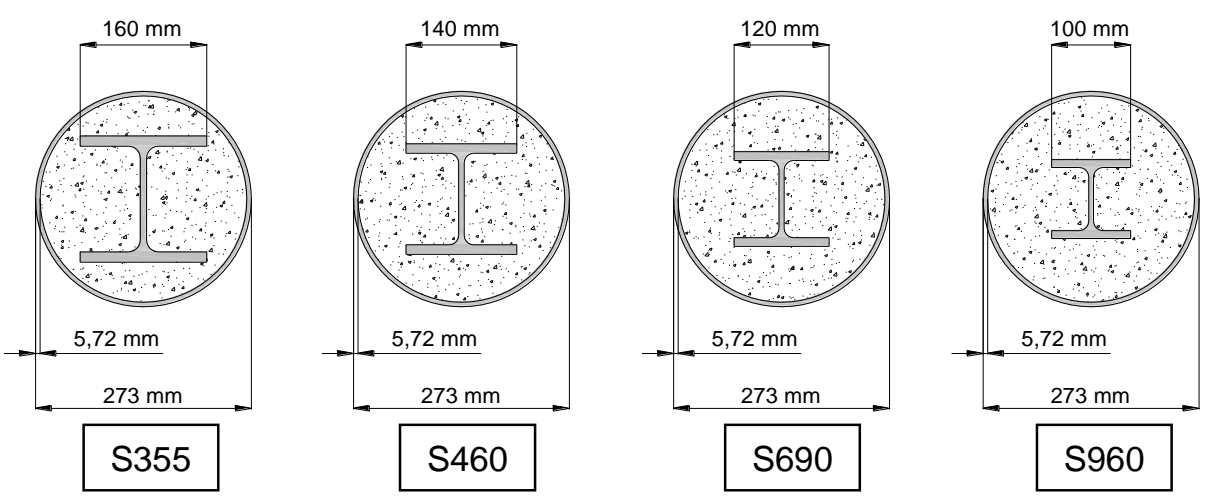

c)
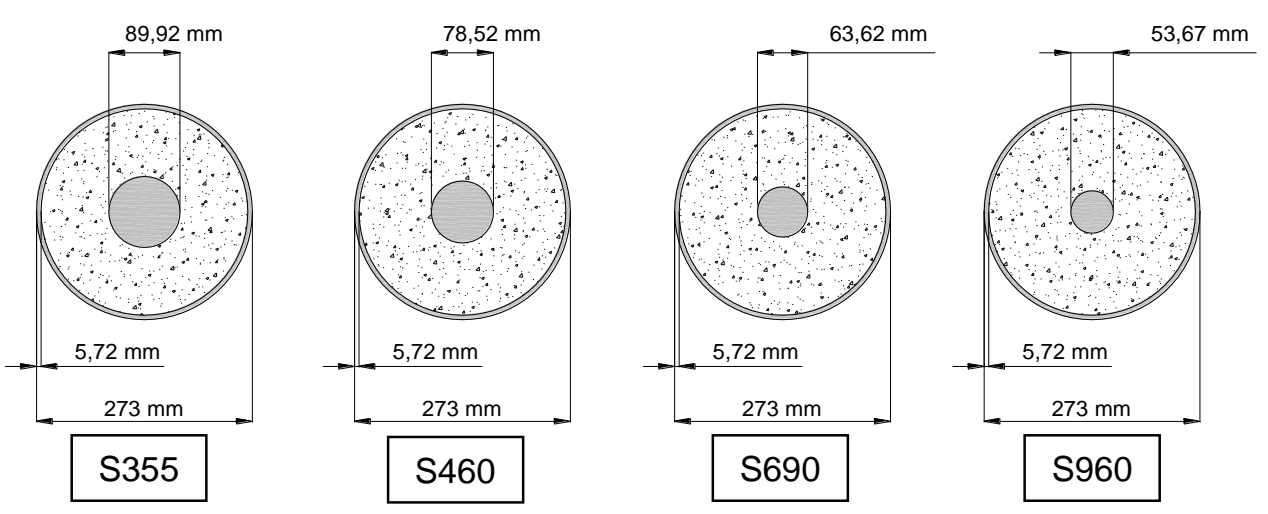

Fig. 11. Cross-sectional dimensions used in the parametric studies (SERIES 2): a) CFDST; b) CFST-HEB; c) CFSTES. 
Espinos A, Romero ML, Lam D. Fire performance of innovative steel-concrete composite columns using high strength steels.

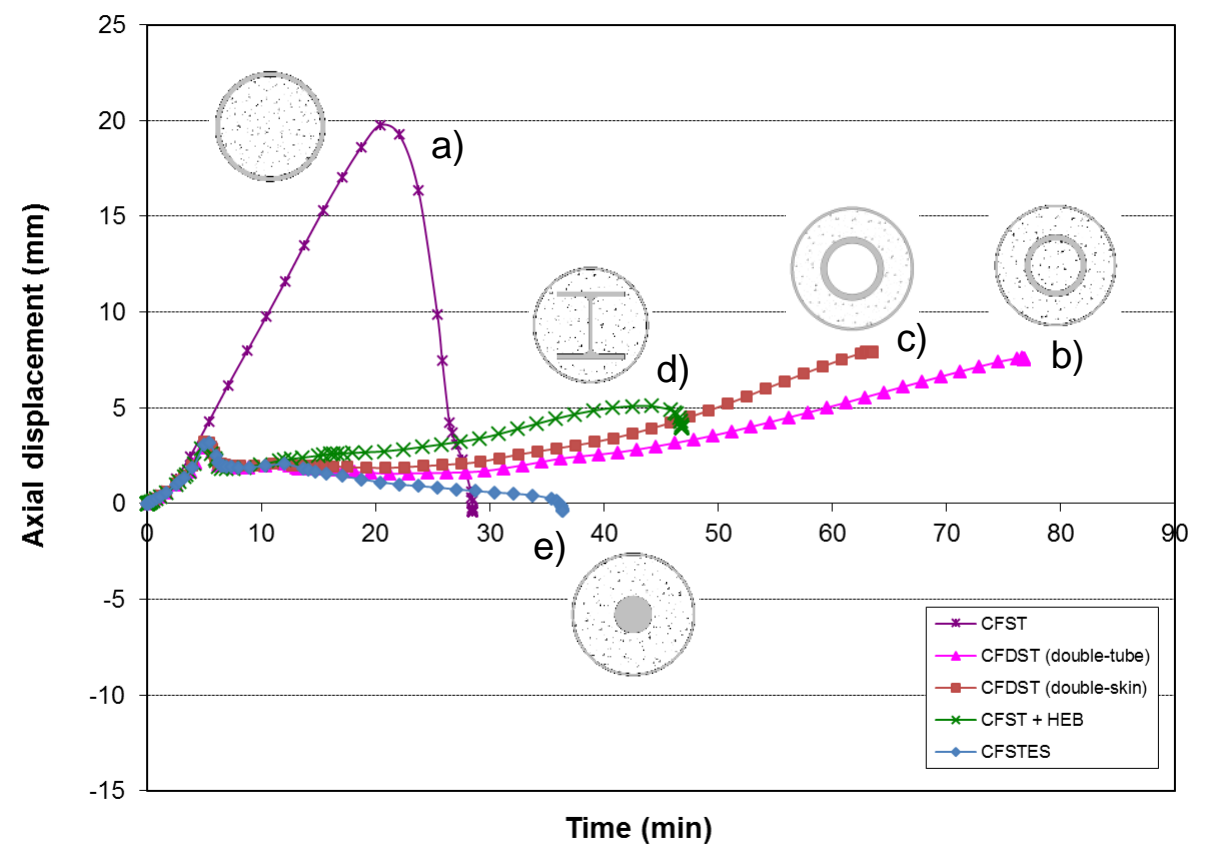

Fig. 12. Comparison between the fire response of the different cross-section configurations studied in SERIES 1, using S355 steel: a) CFST; b) CFDST (double-tube); c) CFDST (doubleskin); d) CFST-HEB; e) CFSTES. 
Espinos A, Romero ML, Lam D. Fire performance of innovative steel-concrete composite columns using high strength steels.

a)

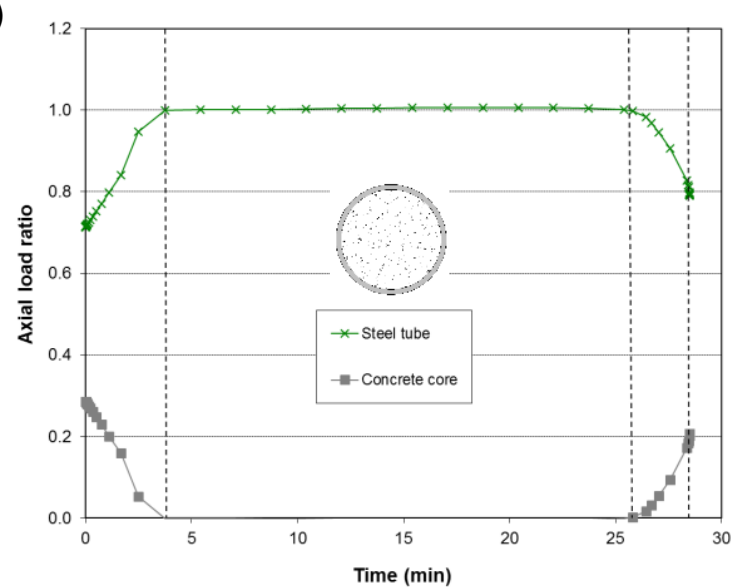

c)

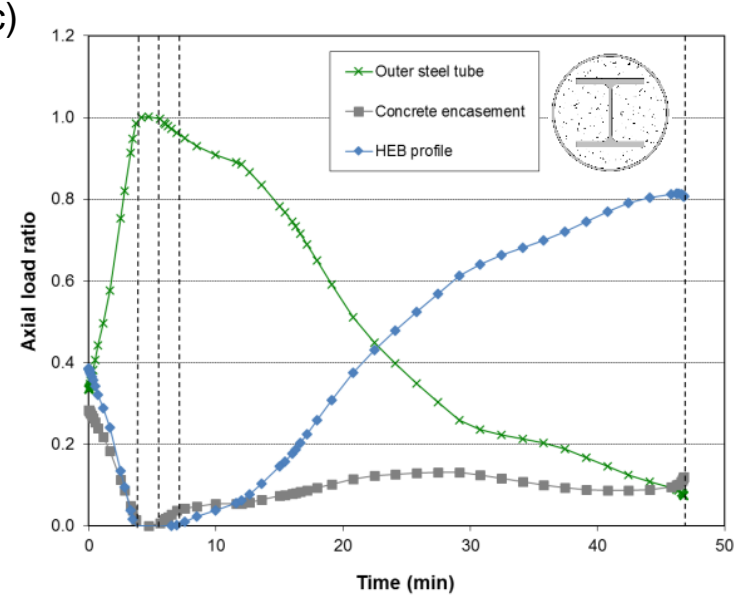

b)

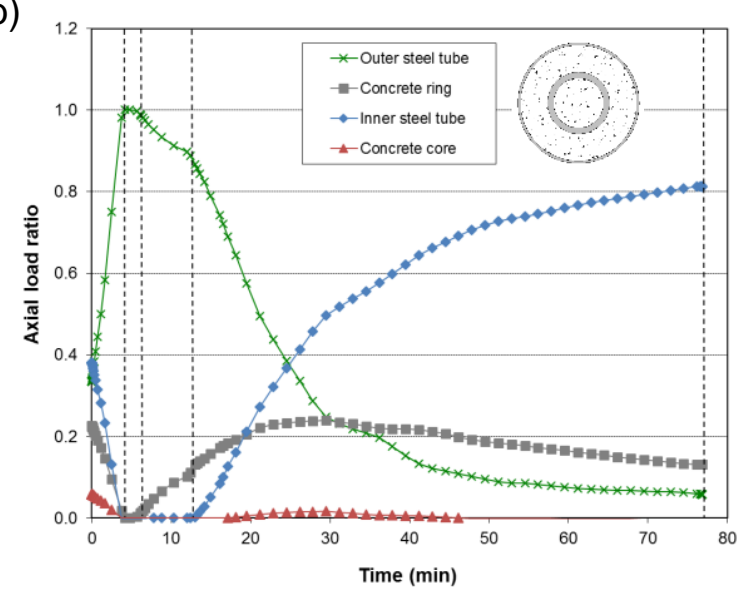

d)

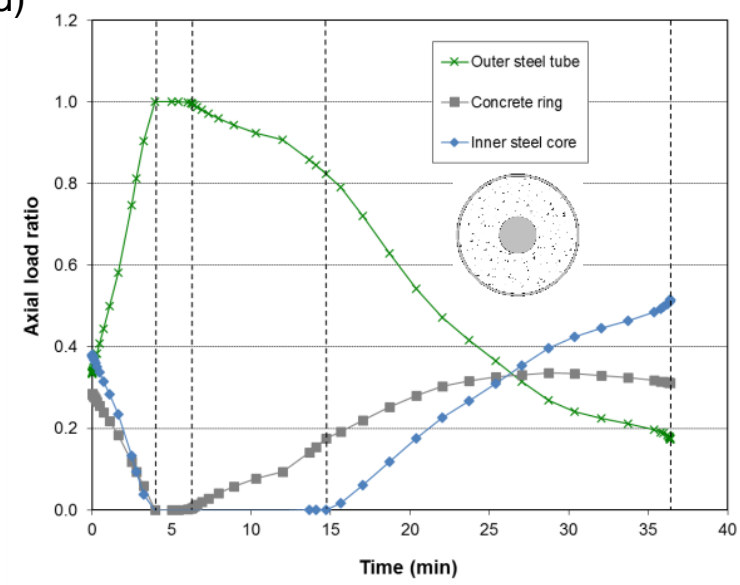

Fig. 13. Evolution of the axial load ratio of the different components of the composite sections studied: a) CFST; b) CFDST (double-tube); c) CFST-HEB; d) CFSTES. 


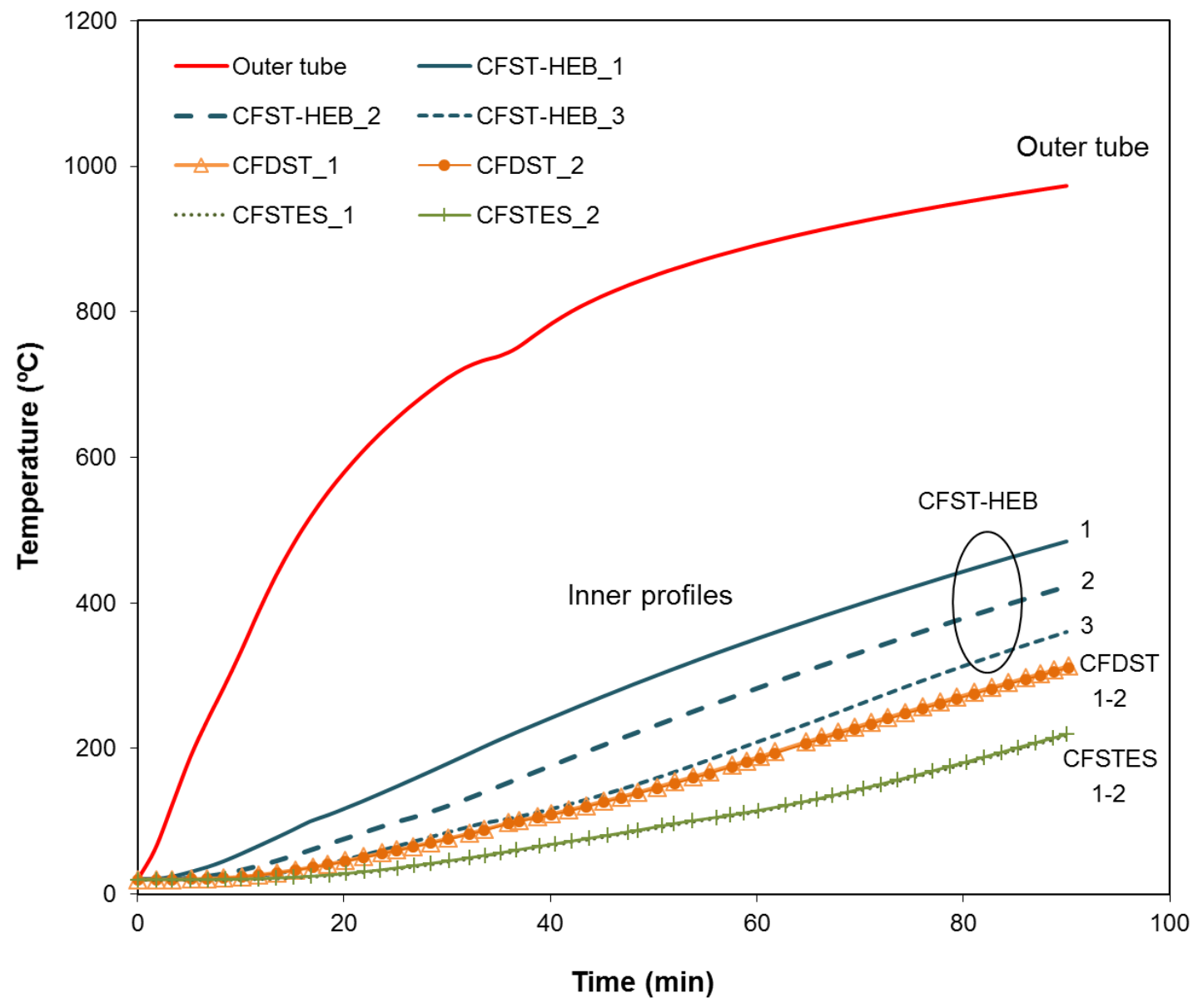

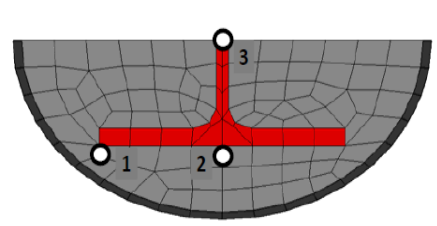

CFST-HEB

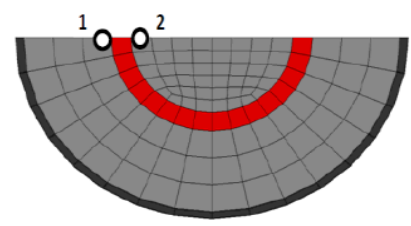

CFDST

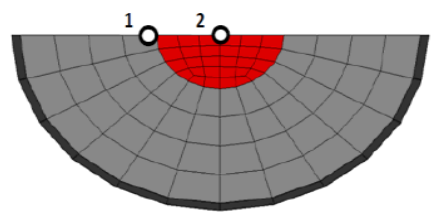

CFSTES

Fig. 14. Comparison of the temperature field of the different cross-sections studied in SERIES 1, after 90 minutes of fire exposure. 
a)

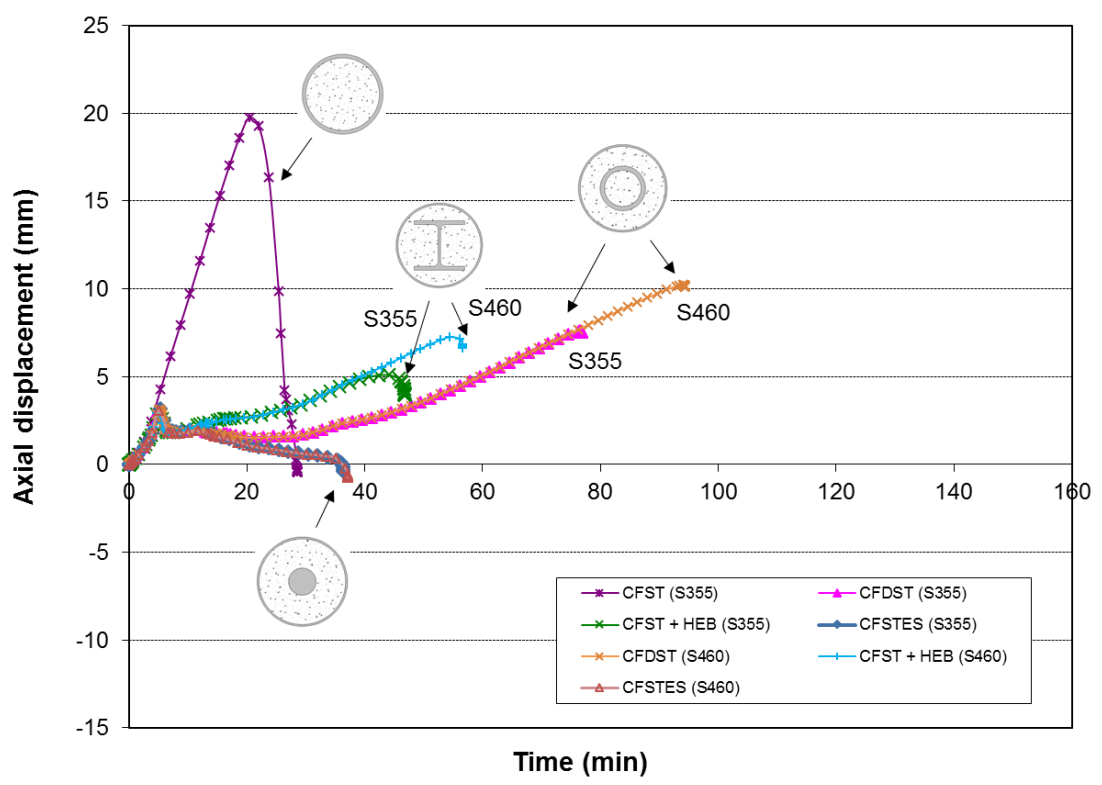

b)

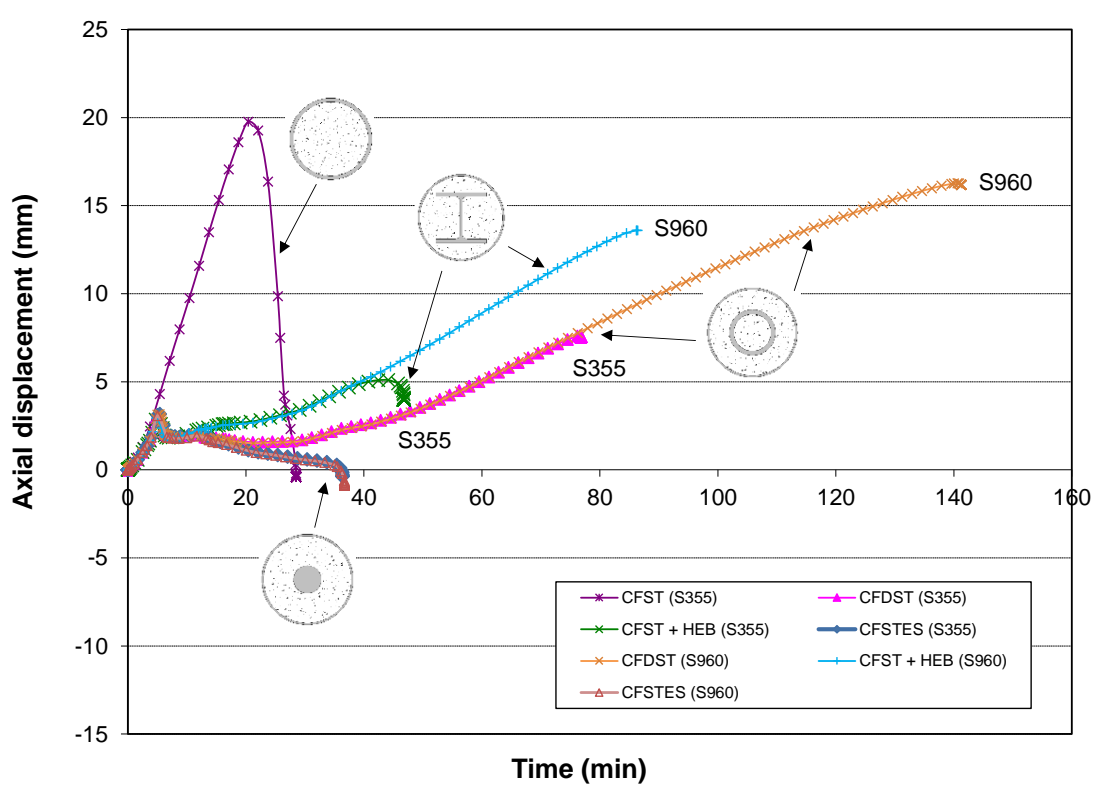

Fig. 15. Comparison between the fire behaviour of the cross-section configurations studied, using different steel grades and equal steel area (SERIES 1): a) S355 vs S460, b) S355 vs S960. 
Espinos A, Romero ML, Lam D. Fire performance of innovative steel-concrete composite columns using high strength steels.

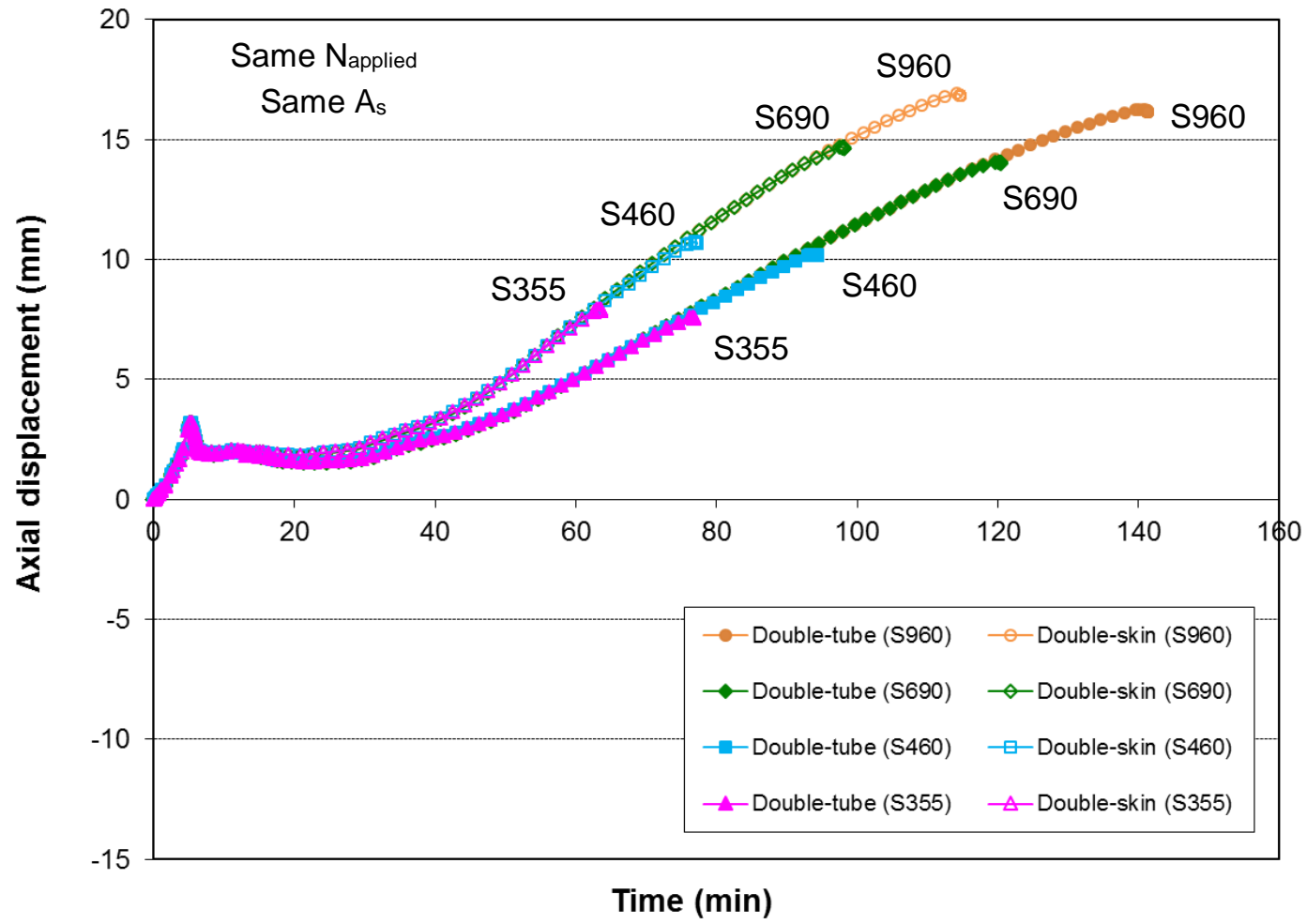

Fig. 16. Enhancement in fire resistance obtained by using HSS in the inner steel tube whilst maintaining the total steel area, for CFDST sections. 
Espinos A, Romero ML, Lam D. Fire performance of innovative steel-concrete composite columns using high strength steels.

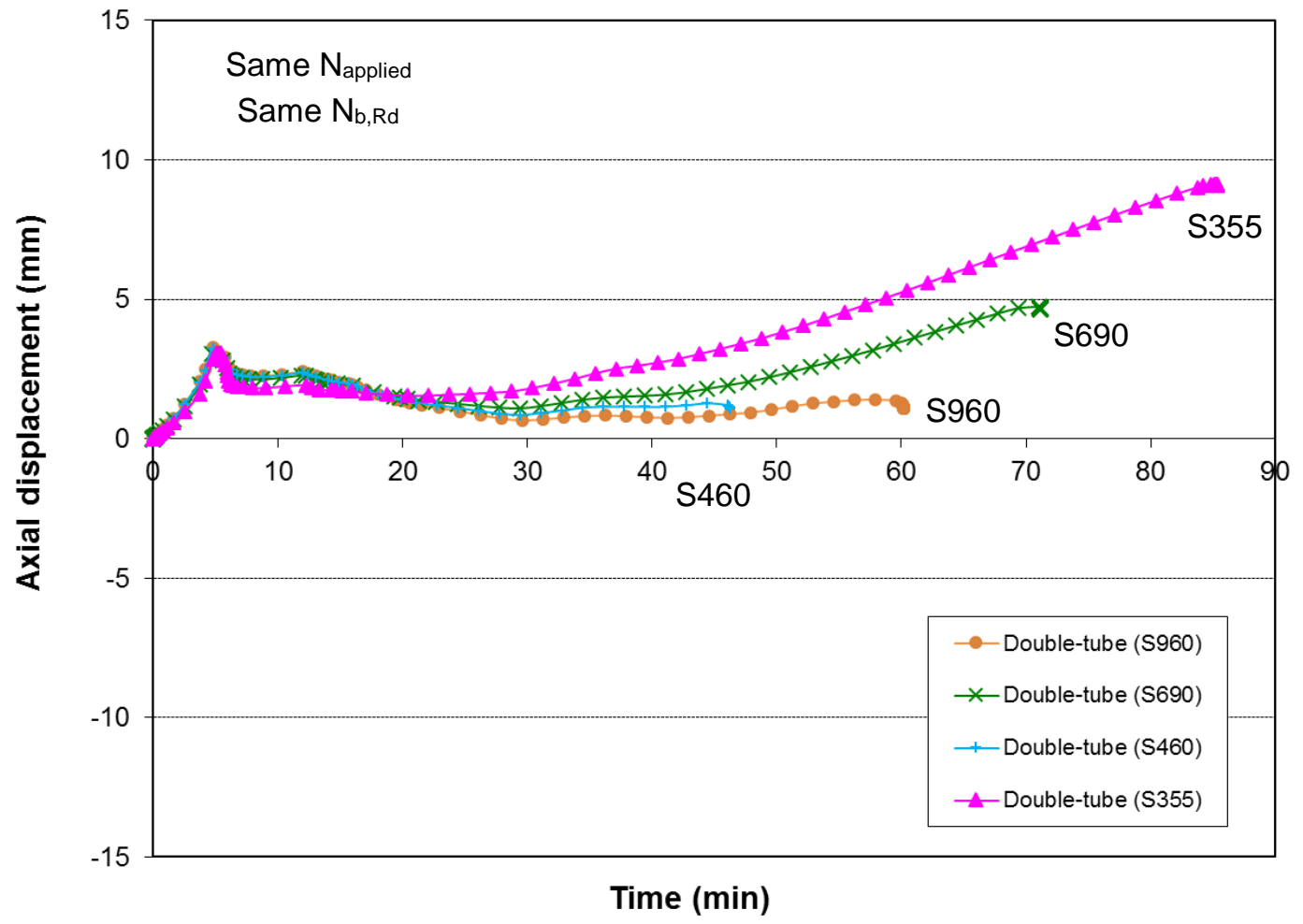

Fig. 17. Effect of using HSS in the inner steel tube whilst maintaining the load-bearing capacity at room temperature, for CFDST sections. 
a)

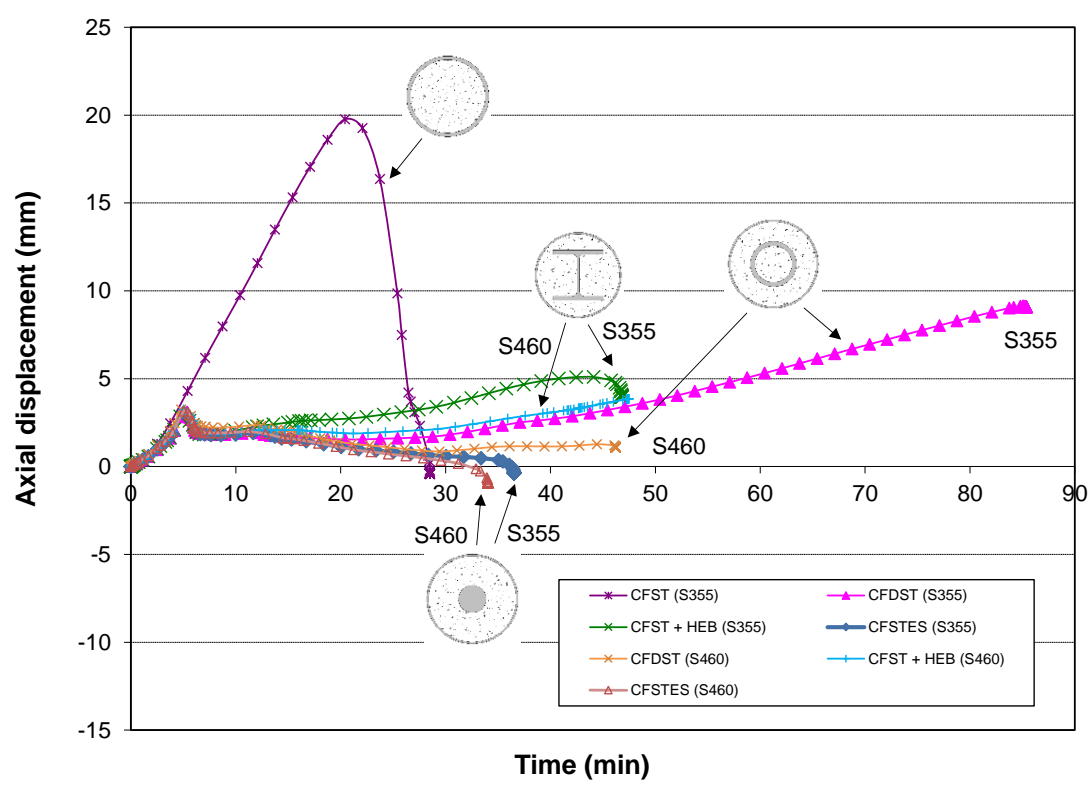

b)

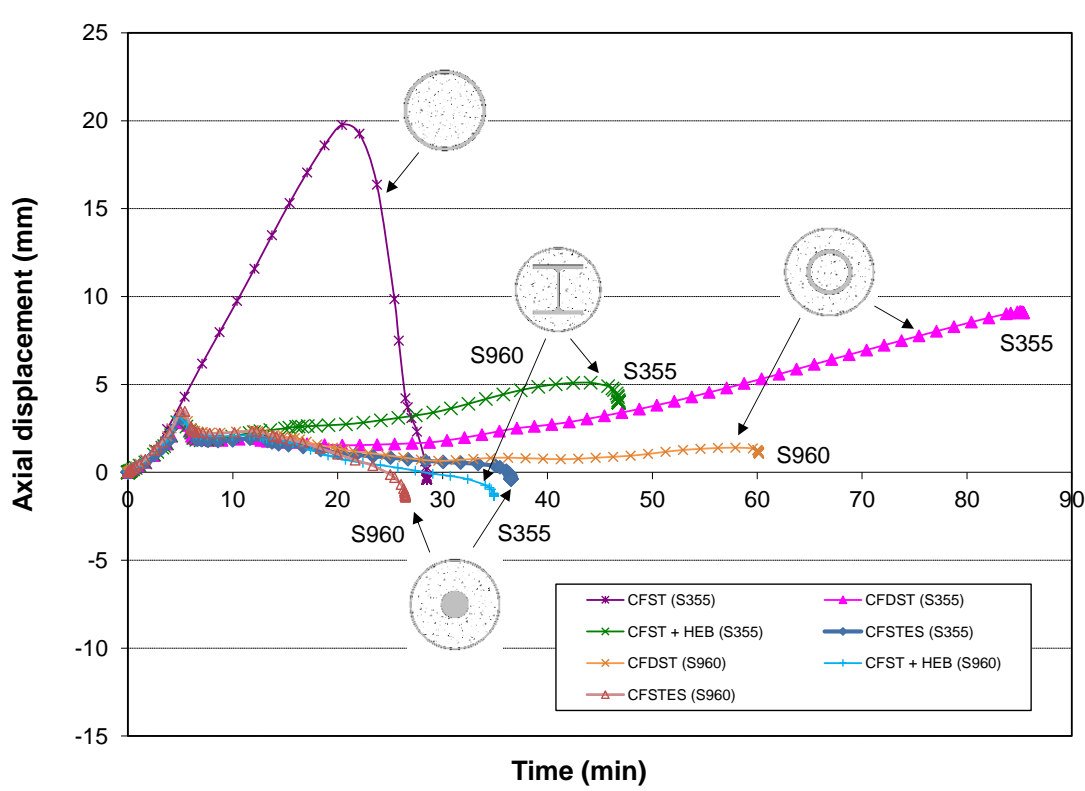

Fig. 18. Comparison between the fire behaviour of the cross-section configurations studied, using different steel grades and equal room temperature capacity (SERIES 2): a) S355 vs S460, b) S355 vs S960. 
Table 1. Input data of the column specimens used for validation

a) Fire tests on double-skin and double-tube CFST columns (type I)

\begin{tabular}{|c|c|c|c|c|c|c|c|c|c|c|c|c|c|}
\hline Specimen & $D_{o}(\mathbf{m m})$ & $t_{o}(\mathbf{m m})$ & $\begin{array}{c}f_{y o} \\
(\mathbf{M P a})\end{array}$ & $\begin{array}{c}f_{c o} \\
(\mathbf{M P a})\end{array}$ & $\begin{array}{c}D_{i} \\
(\mathbf{m m})\end{array}$ & $\begin{array}{c}\boldsymbol{t}_{\boldsymbol{i}} \\
(\mathbf{m m})\end{array}$ & $\begin{array}{c}f_{y i} \\
(\mathbf{M P a})\end{array}$ & $\begin{array}{c}f_{c i} \\
(\mathbf{M P a})\end{array}$ & $\begin{array}{c}L \\
(\mathbf{m m})\end{array}$ & B.C. & $\begin{array}{c}\boldsymbol{e} \\
(\mathbf{m m})\end{array}$ & $\begin{array}{c}\text { Load } \\
(\mathbf{k N})\end{array}$ & $\begin{array}{l}\text { Time } \\
\text { (min) }\end{array}$ \\
\hline C200-3-30-C114-8-00 [17] & 200 & 3 & 300 & 46 & 114.3 & 8 & 377 & - & 3180 & P-P & 0 & 283 & 76 \\
\hline $\mathrm{C} 200-3-30-\mathrm{C} 114-8-30$ [17] & 200 & 3 & 332 & 46 & 114.3 & 8 & 403 & 45 & 3180 & P-P & 0 & 325 & 104 \\
\hline C200-6-30-C114-3-00 [17] & 200 & 6 & 407 & 43 & 114.3 & 3 & 343 & - & 3180 & P-P & 0 & 329 & 48 \\
\hline C200-6-30-C114-3-30 [17] & 200 & 6 & 377 & 44 & 114.3 & 3 & 329 & 42 & 3180 & P-P & 0 & 392 & 45 \\
\hline $\mathrm{CC} 2[14]$ & 300 & 5 & 320 & $38^{(1)}$ & 125 & 5 & 320 & - & 3810 & P-F & 75 & 570 & 97 \\
\hline CC3[14] & 300 & 5 & 320 & $38^{(1)}$ & 225 & 5 & 320 & - & 3810 & $\mathrm{P}-\mathrm{F}$ & 0 & 2000 & 40 \\
\hline
\end{tabular}

b) Fire tests on CFST columns with embedded HEB profile (type II)

\begin{tabular}{cccccccccccc}
\hline Specimen & $\boldsymbol{D}_{\boldsymbol{o}}(\mathbf{m m})$ & $\boldsymbol{t}_{\boldsymbol{o}}(\mathbf{m m})$ & $\begin{array}{c}\boldsymbol{f}_{\boldsymbol{y}} \\
(\mathbf{M P a})\end{array}$ & $\begin{array}{c}\text { Internal } \\
\text { profile }\end{array}$ & $\begin{array}{c}\boldsymbol{f}_{\boldsymbol{y i}} \\
(\mathbf{M P a})\end{array}$ & $\begin{array}{c}\boldsymbol{f}_{\boldsymbol{c}} \\
(\mathbf{M P a})\end{array}$ & $\begin{array}{c}\boldsymbol{L} \\
(\mathbf{m m})\end{array}$ & B.C. & $\begin{array}{c}\boldsymbol{e} \\
(\mathbf{m m})\end{array}$ & $\begin{array}{c}\text { Load } \\
(\mathbf{k N})\end{array}$ & $\begin{array}{c}\text { Time } \\
(\mathbf{m i n})\end{array}$ \\
\hline 3A [20] & 219.1 & 5 & 420 & HEB120 & 375 & 35 & 3310 & $\mathrm{P}-\mathrm{P}$ & 10 & 946 & 56 \\
4A [20] & 200 & 5 & 510 & HEB120 & 375 & 35 & 3310 & P-P & 10 & 1177 & 39 \\
\hline
\end{tabular}

c) Fire tests on CFST columns with embedded steel core (type III)

\begin{tabular}{cccccccccccc}
\hline Specimen & $\boldsymbol{D}_{\boldsymbol{o}}(\mathbf{m m})$ & $\boldsymbol{t}_{\boldsymbol{o}}(\mathbf{m m})$ & $\begin{array}{c}\boldsymbol{f}_{\boldsymbol{y}} \\
(\mathbf{M P a})\end{array}$ & $\begin{array}{c}\boldsymbol{D}_{\text {core }} \\
(\mathbf{m m})\end{array}$ & $\begin{array}{c}\boldsymbol{f}_{\mathbf{y}, \text { core }} \\
(\mathbf{M P a})\end{array}$ & $\begin{array}{c}\boldsymbol{f}_{\boldsymbol{c}} \\
(\mathbf{M P a})\end{array}$ & $\begin{array}{c}\boldsymbol{L} \\
(\mathbf{m m})\end{array}$ & B.C. & $\begin{array}{c}\boldsymbol{e} \\
(\mathbf{m m})\end{array}$ & $\begin{array}{c}\text { Load } \\
(\mathbf{k N})\end{array}$ & $\begin{array}{c}\text { Time } \\
(\mathbf{m i n})\end{array}$ \\
\hline SP1 [23] & 133 & 4 & $235^{(1)}$ & 60 & $355^{(1)}$ & $25^{(2)}$ & 3540 & $\mathrm{P}-\mathrm{P}$ & 10 & 85 & 94 \\
SP2 [23] & 219.1 & 4.5 & $235^{(1)}$ & 110 & $355^{(1)}$ & $25^{(2)}$ & 3600 & $\mathrm{P}-\mathrm{F}$ & 10 & 2000 & 24 \\
SP3 [23] & 219.1 & 4.5 & $235^{(1)}$ & 110 & $355^{(1)}$ & $25^{(2)}$ & 3600 & P-F & 10 & 1500 & 169 \\
SP4 [23] & 219.1 & 4.5 & $235^{(1)}$ & 150 & $355^{(1)}$ & $25^{(2)}$ & 3600 & P-F & 10 & 1900 & 178 \\
CFSTES [25] & 219.1 & 4.5 & 308.2 & 140 & 349 & 27.5 & 3560 & P-F & 7 & 1800 & $>90$ \\
\hline
\end{tabular}

d) Fire tests on CFST columns with HSS

\begin{tabular}{cccccccccccc}
\hline Specimen & $\boldsymbol{D}_{\boldsymbol{o}}(\mathbf{m m})$ & $\boldsymbol{t}_{\boldsymbol{o}}(\mathbf{m m})$ & Rebars & $\begin{array}{c}\boldsymbol{f}_{\boldsymbol{y}} \\
(\mathbf{M P a})\end{array}$ & $\begin{array}{c}\boldsymbol{f}_{\boldsymbol{s}} \\
(\mathbf{M P a})\end{array}$ & $\begin{array}{c}\boldsymbol{f}_{\boldsymbol{c}} \\
(\mathbf{M P a})\end{array}$ & $\begin{array}{c}\boldsymbol{L} \\
(\mathbf{m m})\end{array}$ & B.C. & $\begin{array}{c}\boldsymbol{e} \\
(\mathbf{m m})\end{array}$ & $\begin{array}{c}\text { Load } \\
(\mathbf{k N})\end{array}$ & $\begin{array}{c}\text { Time } \\
(\mathbf{m i n})\end{array}$ \\
\hline $\mathrm{C} 4[29]$ & 355.6 & 12 & $8 \phi 18$ & 822 & 546 & 55.1 & 3150 & $\mathrm{P}-\mathrm{P}$ & 10 & 2000 & 109 \\
\hline
\end{tabular}


Table 2. Comparison between numerical and experimental failure time

\begin{tabular}{cccc}
\hline Specimen & Test & Num. & Test/Num. \\
\hline Type I (CFDST) & & & \\
\hline C200-3-30-C114-8-00 [17] & 76 & 69 & 1.10 \\
C200-3-30-C114-8-30 [17] & 104 & 94 & 1.11 \\
C200-6-30-C114-3-00 [17] & 48 & 38 & 1.26 \\
C200-6-30-C114-3-30 [17] & 45 & 44 & 1.02 \\
CC2 [14] & 97 & 96 & 1.02 \\
CC3 [14] & 40 & 39 & 1.03 \\
\hline Type II (CFST-HEB) & & & \\
\hline 3A [20] & 56 & 46 & 1.22 \\
4A [20] & 39 & 38 & 1.03 \\
\hline Type III (CFSTES) & & & \\
\hline SP1 [23] & 94 & 90 & 1.04 \\
SP2 [23] & 24 & 23 & 1.04 \\
SP3 [23] & 169 & 107 & 1.58 \\
SP4 [23] & 178 & 130 & 1.37 \\
\hline CFST columns with HSS & & \\
\hline C4 [29] & 109 & 114 & 0.96 \\
\hline Mean & & & $\mathbf{1 . 1 4}$ \\
\hline Std. dev. & & $\mathbf{0 . 1 8}$ \\
\hline
\end{tabular}


Table 3. Comparison of geometrical and mechanical features of the selected innovative columns with equal steel cross-sectional area (SERIES 1)

\begin{tabular}{ccccccccccccc}
\hline Specimen & $\begin{array}{c}\text { Outer } \\
\text { profile }\end{array}$ & $\begin{array}{c}\text { Inner } \\
\text { profile }\end{array}$ & $\begin{array}{c}\boldsymbol{A}_{\boldsymbol{s}} \\
\left(\mathbf{m m}^{\mathbf{2}}\right)\end{array}$ & $\begin{array}{c}\boldsymbol{A}_{\boldsymbol{c}} \\
\left(\mathbf{m m}^{\mathbf{2}}\right)\end{array}$ & $\begin{array}{c}\boldsymbol{f}_{\boldsymbol{y} \boldsymbol{o}} \\
(\mathbf{M P a})\end{array}$ & $\begin{array}{c}\boldsymbol{f}_{\boldsymbol{y} i} \\
(\mathbf{M P a})\end{array}$ & $\bar{\lambda}$ & $\begin{array}{c}\boldsymbol{N}_{\boldsymbol{b}, \boldsymbol{R} \boldsymbol{d}} \\
(\mathbf{k N})\end{array}$ & $\begin{array}{c}\boldsymbol{N}_{\boldsymbol{b}, \boldsymbol{R} \boldsymbol{d}} / \\
\boldsymbol{N}_{\boldsymbol{b}, \boldsymbol{R} \boldsymbol{d}(\mathbf{C F S T})}\end{array}$ & $\begin{array}{c}\boldsymbol{N}_{a p p l i e d} \\
(\mathbf{k N})\end{array}$ & $\begin{array}{c}\boldsymbol{\mu} \\
(\boldsymbol{\%})\end{array}$ & $\begin{array}{c}\text { Time } \\
(\mathbf{m i n})\end{array}$ \\
\hline CFST & $273 \times 12.5$ & - & 10230 & 48305 & 355 & - & 0.50 & 4697 & 1 & 1409 & 0.30 & 28 \\
\hline CFDST-01a & $273 \times 5.72$ & $139.7 \times 13.71$ & 10230 & 48305 & 355 & 355 & 0.59 & 4533 & 0.97 & 1409 & 0.31 & 77 \\
CFDST-02a & $273 \times 5.72$ & $139.7 \times 13.71$ & 10230 & 48305 & 355 & 460 & 0.63 & 4971 & 1.06 & 1409 & 0.28 & 94 \\
CFDST-03a & $273 \times 5.72$ & $139.7 \times 13.71$ & 10230 & 48305 & 355 & 690 & 0.69 & 5873 & 1.25 & 1409 & 0.24 & 120 \\
CFDST-04a & $273 \times 5.72$ & $139.7 \times 13.71$ & 10230 & 48305 & 355 & 960 & 0.76 & 6830 & 1.45 & 1409 & 0.21 & 141 \\
\hline CFDST-01b & $273 \times 5.72$ & $139.7 \times 13.71$ & 10230 & - & 355 & 355 & 0.58 & 4295 & 0.91 & 1409 & 0.33 & 63 \\
CFDST-02b & $273 \times 5.72$ & $139.7 \times 13.71$ & 10230 & - & 355 & 460 & 0.61 & 4739 & 1.01 & 1409 & 0.30 & 77 \\
CFDST-03b & $273 \times 5.72$ & $139.7 \times 13.71$ & 10230 & - & 355 & 690 & 0.68 & 5656 & 1.20 & 1409 & 0.25 & 98 \\
CFDST-04b & $273 \times 5.72$ & $139.7 \times 13.71$ & 10230 & - & 355 & 960 & 0.75 & 6631 & 1.41 & 1409 & 0.21 & 115 \\
\hline CFST-HEB-01 & $273 \times 5.72$ & HEB160 & 10230 & 48305 & 355 & 355 & 0.60 & 4519 & 0.96 & 1409 & 0.31 & 47 \\
CFST-HEB-02 & $273 \times 5.72$ & HEB160 & 10230 & 48305 & 355 & 460 & 0.63 & 4952 & 1.05 & 1409 & 0.28 & 57 \\
CFST-HEB-03 & $273 \times 5.72$ & HEB160 & 10230 & 48305 & 355 & 690 & 0.70 & 5845 & 1.24 & 1409 & 0.24 & 71 \\
CFST-HEB-04 & $273 \times 5.72$ & HEB160 & 10230 & 48305 & 355 & 960 & 0.77 & 6787 & 1.44 & 1409 & 0.21 & 86 \\
\hline CFSTES-01 & $273 \times 5.72$ & $\phi 83.12$ & 10230 & 48305 & 355 & 355 & 0.63 & 4465 & 0.95 & 1409 & 0.32 & 36 \\
CFSTES-02 & $273 \times 5.72$ & $\phi 83.12$ & 10230 & 48305 & 355 & 460 & 0.66 & 4885 & 1.04 & 1409 & 0.29 & 37 \\
CFSTES-03 & $273 \times 5.72$ & $\phi 83.12$ & 10230 & 48305 & 355 & 690 & 0.73 & 5740 & 1.22 & 1409 & 0.25 & 37 \\
CFSTES-04 & $273 \times 5.72$ & $\phi 83.12$ & 10230 & 48305 & 355 & 960 & 0.81 & 6624 & 1.41 & 1409 & 0.21 & 37 \\
\hline
\end{tabular}

For all the columns, $L=3240 \mathrm{~mm}$, B.C. $=\mathrm{P}-\mathrm{P}, f_{c}=30 \mathrm{MPa}$ 
Table 4. Comparison of geometrical and mechanical features of the selected innovative columns with equal room temperature capacity (SERIES 2)

\begin{tabular}{|c|c|c|c|c|c|c|c|c|c|c|c|c|}
\hline Specimen & $\begin{array}{c}\text { Outer } \\
\text { profile }\end{array}$ & $\begin{array}{c}\text { Inner } \\
\text { profile }\end{array}$ & $\begin{array}{c}A_{s} \\
\left(\mathbf{m m}^{2}\right)\end{array}$ & $\begin{array}{c}A_{s} / \\
A_{s(\text { CFST })} \\
\end{array}$ & $\begin{array}{c}A_{c} \\
\left(\mathbf{m m}^{2}\right)\end{array}$ & $\begin{array}{c}f_{y o} \\
(\mathbf{M P a})\end{array}$ & $\begin{array}{c}f_{y i} \\
(\mathbf{M P a}) \\
\end{array}$ & $\bar{\lambda}$ & $\begin{array}{l}N_{b, R d} \\
(\mathbf{k N})\end{array}$ & $\begin{array}{c}N_{\text {applied }} \\
(\mathbf{k N})\end{array}$ & $\begin{array}{c}\mu \\
(\%) \\
\end{array}$ & $\begin{array}{l}\text { Time } \\
\text { (min) }\end{array}$ \\
\hline CFST & $273 \times 12.5$ & - & 10230 & 1 & 48305 & 355 & - & 0.50 & 4697 & 1409 & 0.30 & 28 \\
\hline CFDST-05 & $273 \times 5.72$ & $139.7 \times 15.50$ & 10850 & 1.06 & 47685 & 355 & 355 & 0.60 & 4697 & 1409 & 0.30 & 85 \\
\hline CFDST-06 & $273 \times 5.72$ & $139.7 \times 11.48$ & 9427 & 0.92 & 49108 & 355 & 460 & 0.61 & 4697 & 1409 & 0.30 & 46 \\
\hline CFDST-07 & $273 \times 5.72$ & $139.7 \times 7.36$ & 7863 & 0.77 & 50672 & 355 & 690 & 0.63 & 4697 & 1409 & 0.30 & 71 \\
\hline CFDST-08 & $273 \times 5.72$ & $139.7 \times 5.19$ & 6998 & 0.68 & 51537 & 355 & 960 & 0.63 & 4697 & 1409 & 0.30 & 60 \\
\hline CFST-HEB-05 & $273 \times 5.72$ & HEB160 & 10230 & 1.00 & 48305 & 355 & 355 & 0.60 & 4519 & 1409 & 0.31 & 47 \\
\hline CFST-HEB-06 & $273 \times 5.72$ & HEB140 & 9100 & 0.89 & 49435 & 355 & 460 & 0.62 & 4556 & 1409 & 0.31 & 47 \\
\hline CFST-HEB-07 & $273 \times 5.72$ & HEB 120 & 8200 & 0.80 & 50335 & 355 & 690 & 0.65 & 4828 & 1409 & 0.29 & 44 \\
\hline CFST-HEB-08 & $273 \times 5.72$ & HEB100 & 7400 & 0.72 & 51135 & 355 & 960 & 0.67 & 4936 & 1409 & 0.29 & 35 \\
\hline CFSTES-05 & $273 \times 5.72$ & $\phi 89.92$ & 11153 & 1.09 & 47382 & 355 & 355 & 0.64 & 4697 & 1409 & 0.30 & 36 \\
\hline CFSTES-06 & $273 \times 5.72$ & $\phi 78.52$ & 9646 & 0.94 & 48889 & 355 & 460 & 0.65 & 4697 & 1409 & 0.30 & 34 \\
\hline CFSTES-07 & $273 \times 5.72$ & $\phi 63.62$ & 7981 & 0.78 & 50553 & 355 & 690 & 0.66 & 4697 & 1409 & 0.30 & 28 \\
\hline CFSTES-08 & $273 \times 5.72$ & $\phi 53.67$ & 7065 & 0.69 & 51470 & 355 & 960 & 0.66 & 4697 & 1409 & 0.30 & 26 \\
\hline
\end{tabular}

For all the columns, $L=3240 \mathrm{~mm}$, B.C. $=\mathrm{P}-\mathrm{P}, f_{c}=30 \mathrm{MPa}$ 


\section{LIST OF FIGURE CAPTIONS}

Fig. 1. Types of composite sections studied in this paper.

Fig. 2. Finite element mesh for the different type of columns analysed.

Fig. 3. Yield strength reduction factors at elevated temperatures for HSS from Qiang [28], as compared to S355 steel.

Fig. 4. Validation of the numerical model for section type I, tests from Romero et al. [17]: a) C200-3-30_C114-8-00 (double-skin); b) C200-3-30_C114-8-30 (double-tube).

Fig. 5. Validation of the numerical model for section type I, tests from Lu et al. [14]: a) specimen $\mathrm{CC} 2$; b) specimen $\mathrm{CC} 3$.

Fig. 6. Validation of the numerical model for section type II, tests from Dotreppe et al. [20]: a) specimen $3 \mathrm{~A}, \mathrm{~b}$ ) specimen $4 \mathrm{~A}$.

Fig. 7. Validation of the numerical model for section type III: a) specimen SP1 from Neuenschwander et al. [23], b) test from Schaumann and Kleiboemer [25].

Fig. 8. Validation of the numerical model for HSS, specimen C4 from Tondini et al. [29].

Fig. 9. Comparison between test results and numerical results, for all the columns analysed.

Fig. 10. Cross-sectional dimensions used in the parametric studies (SERIES 1): a) CFST; b) CFDST; c) CFST-HEB; d) CFSTES.

Fig. 11. Cross-sectional dimensions used in the parametric studies (SERIES 2): a) CFDST; b) CFST-HEB; c) CFSTES.

Fig. 12. Comparison between the fire response of the different cross-section configurations studied in SERIES 1, using S355 steel: a) CFST; b) CFDST (double-tube); c) CFDST (double-skin); d) CFST-HEB; e) CFSTES.

Fig. 13. Evolution of the axial load ratio of the different components of the composite sections studied: a) CFST; b) CFDST (double-tube); c) CFST-HEB; d) CFSTES.

Fig. 14. Comparison of the temperature field of the different cross-sections studied in SERIES 1, after 90 minutes of fire exposure.

Fig. 15. Comparison between the fire behaviour of the cross-section configurations studied, using different steel grades and equal steel area (SERIES 1): a) S355 vs S460, b) S355 vs S960.

Fig. 16. Enhancement in fire resistance obtained by using HSS in the inner steel tube whilst maintaining the total steel area, for CFDST sections.

Fig. 17. Effect of using HSS in the inner steel tube whilst maintaining the load-bearing capacity at room temperature, for CFDST sections.

Fig. 18. Comparison between the fire behaviour of the cross-section configurations studied, using different steel grades and equal room temperature capacity (SERIES 2): a) S355 vs S460, b) S355 vs S960. 


\section{LIST OF TABLE CAPTIONS}

Table 1. Input data of the column specimens used for validation

Table 2. Comparison between numerical and experimental failure time

Table 3. Comparison of geometrical and mechanical features of the selected innovative columns with equal steel cross-sectional area (SERIES 1)

Table 4. Comparison of geometrical and mechanical features of the selected innovative columns with equal room temperature capacity (SERIES 2) 